\title{
Mouse xenograft model of Corticospinal Tract by Delayed Transplantation of Olfactory Ensheating Cells in Adult Rats
}

Maryam

Naghynajadfard

Under the supervision of:

Professor Geoffrey Raisman and Dr Ying Li 


\section{Dedication}

To my beloved parents

Soraya khayatzadeh and Akbar Naghynajdfard 


\section{Abstract}

Adult rats were trained to use their forepaw for retrieving a piece of noodle through a slit in the front of the cage. The dorsal corticospinal tract was lesioned by a focal stereotactic radio-frequency lesion at the level of the first/second cervical segment. Complete destruction of one side of the corticospinal tract completely prevented the use of the ipsilateral forepaw reaching for at least 6 months after operation. Rats which have shown no forepaw retrieval by 8 weeks were xenotransplanted with a suspension of cultured olfactory ensheathing cells derived from the mouse olfactory bulb, into the lesion site. Starting between 1 and 3 weeks, 10 rats with transplants bridging the lesion site resumed ipsilateral forepaw reaching.The histology of the lesioned rats with misplaced olfactory ensheathing cell showed no functional recovery during the 8 weeks of training. 


\section{List of Abbreviations}

AS Albino Swiss Strain

BL Basal lamina

BDNF Brain-derived neurotrophic factor

CFS Cerebral spinal fluid

CNS Central nervous system

CST Corticospinal tract

CSPGs Chondroitin sulphate proteoglycan

DFR Directed Forepaw Retrieval

ESCs Embryonic stem cells

FGF Fibroblast-like Growth Factor

FN Fibronectin

GAG Glycosaminoglycan

GDNF Glial cell line-Derived Feurotropic factor (GDNF)

GFAP Glial Fibrillary Acidic protein

GFP Green Fluorescent Protein

H\&E Hematoxylin \& Eosin

IPSCs Induced pluripotent stem cells

NT-3 Neurotrophin-3

MAG Myelin associated Glycoprotein

MAP Myelin Associated Protein

MSCs Mesenchymal Stem Cells

NSCs Neural Stem Cells 
NF Neurofilament

NgR Nogo-66 Receptor

OECs Olfactory Ensheathing Cells

OMCs Olfactory Mucosa Cell

OPCs Oligodetrocytes progenitor cells

ONF Olfactory nerve fibroblast

PCs Progenitor Cells

P0 Protein Zero Antibody-Neuronal Marker

Rock Rho-associated coiled-coil kinase

$\mathrm{SCl} \quad$ Spinal cord injury

SCs Schwann cells

SCPs Schwann cell precursors

TC Thermocouple

SENAs Stem cell-derived neural aggregates 



\section{Contents}

$\begin{array}{lll}\text { Chapter } 1 & \text { Introduction } & 1\end{array}$

1. General Introduction 3

2. Overview of central nervous system 4

2.1 Central Nervous system embryonic development 5

2.2 Central nervous system 5

2.2.1 Spinal cord $\quad 5$

2.2.1.1 Human Corticospinal (pyramidal) tract $\quad 7$

2.2.1.2 Rat Corticospinal tract 9

3. Overview of Spinal Cord Injury 12

3.1 The response of neuronal cell to spinal cord injury 13

3.1.1The response of astrocytes to spinal cord $\quad 15$

3.1.1.1 Astrocytes in healthy tissue $\quad 15$

3.1.1.2 Glial scar and Reactive Astrogliosis 16

3.2.1 The response of Oligodendrocytes to spinal cord injury 17

$\begin{array}{ll}\text { 4. The repair of spinal cord injury } & 18\end{array}$

4.1 The placement of molecular and cellular bridge in the lesion cavity 18

4.1.1 Embryonic stem cells and induced pluripotent stem cells 18

$\begin{array}{ll}\text { 4.1.2 Mesenchymal stem cells } & 19\end{array}$

$\begin{array}{ll}\text { 4.1.3 Neural stem cells and progenitor cells } & 20\end{array}$

$\begin{array}{ll}\text { 4.1.4 Schwann cells } & 20\end{array}$

$\begin{array}{ll}\text { 4.1.5 Olfactory ensheathing cells } & 21\end{array}$

4.2 The repair of spinal cord injury with growth factor 23

4.3 Neutralizing inhibitors to axonal regeneration $\quad 24$

4.4 Combination therapy 25

5. Olfactory system 26

5.1 Origin 26

5.2 Characterisation $\quad 29$

5.3 Function $\quad 30$

5.4 The role of centrally derived olfactory ensheathing cells 31

5.5 The role of periphery derived olfactory ensheathing cells 32

5.6 Clinical aspects of olfactory ensheathing cells transplantation 33

Objectives $\quad 34$

Chapter $2 \quad$ Material and method $\quad 35$

1. Developing complete unilateral lesions 36 
$\begin{array}{ll}1.2 \text { Perfusion for cryostat sectioning } & 40\end{array}$

1.3 Histology to assess the size of the lesion $\quad 41$

1.4 Histology to study the complete corticospinal tract lesion 42

2. Behavioural Investigation 43

2.1 Behavioural study before lesion making 43

2.2 Behavioural investigation after making the lesion and transplantation $\quad 44$

2.3 Video recording $\quad 45$

3. Delayed repair of complete corticospinal tract lesions by 47 xeno-transplantation of OECs

3.1 Culture of Olfactory ensheathing cells from olfactory bulb 47

$\begin{array}{ll}3.2 & \text { OEC cell suspension preparation }\end{array}$

$\begin{array}{ll}\text { 3.3 The microtransplantaion procedure } & 48\end{array}$

3.4 OECs culture histology $\quad 49$

3.5 Tissue preparation and immunohistochemistry 53

3.6 The study of immunorejection against OEC xenotransplant 53

3.7 The study of fibrotic scar at the long term lesion animals 54

$\begin{array}{lll}\text { Chapter } 3 & \text { Result } & 56\end{array}$

1. Histology images to assess the lesion size before transplantation 58

2.The result of histology images of grafted tissue 59

2.1 Histology images of the effect of immune attack on 59

the grafted tissue without the injection of immunosuppressant agent

2.2 Histology images of transplanted olfactory ensheathing cells in displaced $\quad 61$ position after injection of immunosuppressant agent

2.3 Histology images of xenotransplanted olfactory ensheathing cells in $\quad 62$

complete corticospinal tract lesion after the injection of immunosuppressant agent

2.4 Transplant $\quad 65$

3. The result of Behaviour test result $\quad 66$

3.1 The immunohistochemitry images of long term untransplanted lesion control 69 and behaviour test results

$\begin{array}{lll}\text { Chapter } 4 \quad \text { Discussion } & 70\end{array}$

1. The effect of CST Lesions on DFR function $\quad 71$

2. Restoration of Function by delayed transplantation 72

3. The study of grafted tissue immunorejection $\quad 74$

$\begin{array}{ll}\text { Future plan } & 75\end{array}$

$\begin{array}{ll}\text { References } & 77\end{array}$ 



\section{Chapter 1}

\section{Introduction}

1. General introduction

2. Overview of central nervous system

2.1 Central Nervous system embryonic development

2.2 Central nervous system

\subsubsection{Spinal cord}

2.2.1.1 Human Corticospinal (pyramidal) tract

2.2.1.2 Rat Corticospinal tract

3. Overview of Spinal Cord Injury

3.1 The response of neuronal cell to spinal cord injury

3.1.1 The response of astrocytes to spinal cord injury

3.1.1.1 Astrocytes in healthy tissue

3.1.1.2 Glial scar and Reactive Astrogliosis

3.2.1 The response of Oligodendrocytes to spinal cord injury 
4. The repair of spinal cord injury

4.1 The placement of molecular and cellular bridge in the lesion cavity

4.1.1 Embryonic stem cells and induced pluripotent stem cells

4.1.2 Mesenchymal stem cells

4.1.3 Neural stem cells and progenitor cells

4.1.4 Schwann cells

4.1.5 Olfactory ensheathing cells

4.2 The repair of spinal cord injury with growth factor

4.3 Neutralizing inhibitors to axonal regeneration

4.4 Combination therapy

5. Olfactory system

\subsection{Origin}

5.2 Characterisation

5.3 Function

5.4 The role of centrally derived olfactory ensheathing cells

5.5 The role of periphery derived olfactory ensheathing cells 


\section{General introduction}

It has been reported previously by Jike. Lu, et al.,( 2002) "delayed allograft transplant of Olfactory Ensheathing Cells (OEC) in rat unilateral lesion of the dorsal corticospinal tract (CST) mediate directed forepaw retrieval by ipsilateral forepaw". Base on Ying Li et al., (2003) "The potential value of such an approach to human spinal cord injuries is the repair of delayed cervical spinal cord by 3 months". However as recent studies show the use of auto and allo- transplant of OECs is not practicable for therapeutic use due to inaccessibility to olfactory bulb and unavailability of donors. Also although some scientists use periphery derived OECs, Olfactory Mucosa Cell (OMCs), obtained from small biopsy of olfactory mucosa lamina propria from external nares (nostrils), it is not efficient alternative source is not feasible as the auto and allo-transplant of OM in solid piece and cultured OM cells does not have enough cell numbers (Jike Lu, et al. 2002). At this study, we look at the xenotransplant of olfactory ensheathing cells derived mice olfactory bulb as the OEC cell source in the rat unilateral corticospinal tract lesioned model to retrieve Directed Forepaw Reaching (DFR) with the hope of future therapeutic use of xenotansplant source of OEC cells as an alternative stem cell source to solve some problems such as inaccessibility and unavailability of cell numbers of auto-transplantation of OEC and OM and also the difficulty to find the donor for allograft-transplantation. 


\section{Overview of central nervous system}

\subsection{Central nervous system embryonic development}

The neural development starts from the early stage of embryogenesis (Gastrulation, week 3 in human and days 19-22 in rat) and it is not complete until after birth and some cells continue to be throughout life. According to (Neural system development Net) "The early development of central nervous system begins as a simple neural plate that forms neural groove and fold at each end ". "During the third week of embryogenesis, in gastrulation period, the cylinder of cells extends along the rostral and caudal axis To form neural plate from the outer most layer of ectoderm that forms the neural groove develops after two days and folds at each end to a cranial broad plate region (brain plate) and caudally a narrower plate region (spinal cord) "(Neural system development Net). Neuroectodermal cells form neural crest along each side. The Neural crest later on also gives rise to develop to non-neuronal cells of peripheral nerve, dorsal root ganglia of spinal cord, some of the neurons in sensory ganglia of cranial nerve. The neural tube close to somatic region develops to spinal cord. On each side of neural tube, mesodermal cells are thickened to form somatic cells which develop to musculature and skeletal structures (Neural system development Net). 


\subsection{Central nervous system}

The central nervous system (CNS) is the main part of the nervous system consisting of brain and spinal cord that transfers the message it receives from, and coordinates and influences the activity of the body of bilateral animal in contrast to sponges and radically symmetrical animals e.g. jellyfish. Together with the peripheral nervous system, it has a fundamental role in the control of behaviour.

\subsubsection{Spinal cord}

The segmental nature of the spinal cord is reflected in serious of paired spinal nerves, each of which is attached to the cord by a dorsal sensory root and a ventral motor root. As Maton, A. et al., 1993 explained "The central grey matter, in which neuronal cell bodies are located, has a roughly h-shaped outline in transferred when The white matter, which consists of myelinated axons running longitudinally, occupies Periphery of the cord ". Also based on Maton, A. et al., 1993 "The spinal grey matter includes neuronal connections that provide for spinal reflexes when The white matter contains axons that convey sensory data to the brain and others that conduct impulses typically from the brain to the spinal cord ". 


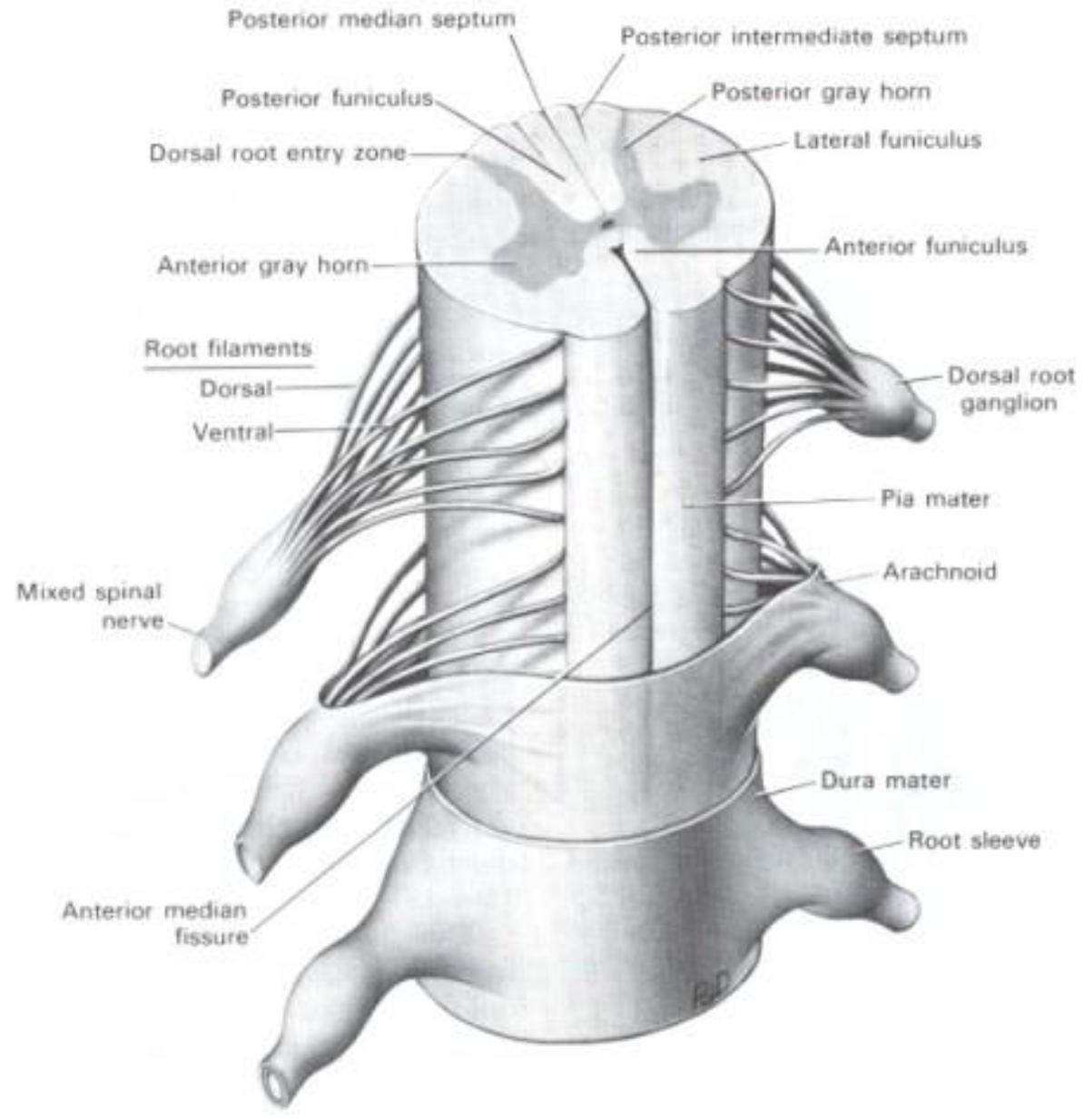

Figure1: Ref: http://www.laesieworks.com/spinal/SClinfo01.html 


\subsubsection{Human Corticospinal (pyramidal) tract}

The parent cell bodies of the corticospinal tract are located in an area of cerebral cortex that occupies adjoining regions of the frontal and parietal lobes. Their axons traverse the subcortical white matter the internal capsule, and the brain stem. In the medulla, each costicospinal tract is a compact body of white matter in the pyramid, in most people almost $85 \%$ of corticospinal tract cross over in the decussating of the pyramids. As Kiernan, J. A. (2005) pointed out "The $15 \%$ of no decussating fibres continue into the ventral funiculus of the cord as the ventral corticospinal tract". As Huang W.I. (2007) explained "corticospinal fibres terminate in the base of the dorsal horn, intermediate grey matter, and the ventral horn: few synapses directly with motor neurons". The widest and the most rapidly conducting ones come the giant pyramidal cells of Betz in the primary motor area: these are the fibres believed to end in synaptic contact with the cell bodies of spinal cord motor neurons. The corticospinal tracts are often thought of having an exclusively motor function, and this is indeed their major function. Many axons of cortical origin arise in the primary somatosensory area. Kiernan, J. A. (2005) explained "However this modulates the transmission of sensory signals to the brain, by synapsing with neurons in the gracile and cuneate nuclei and in the dorsal horn of the spinal cord". 


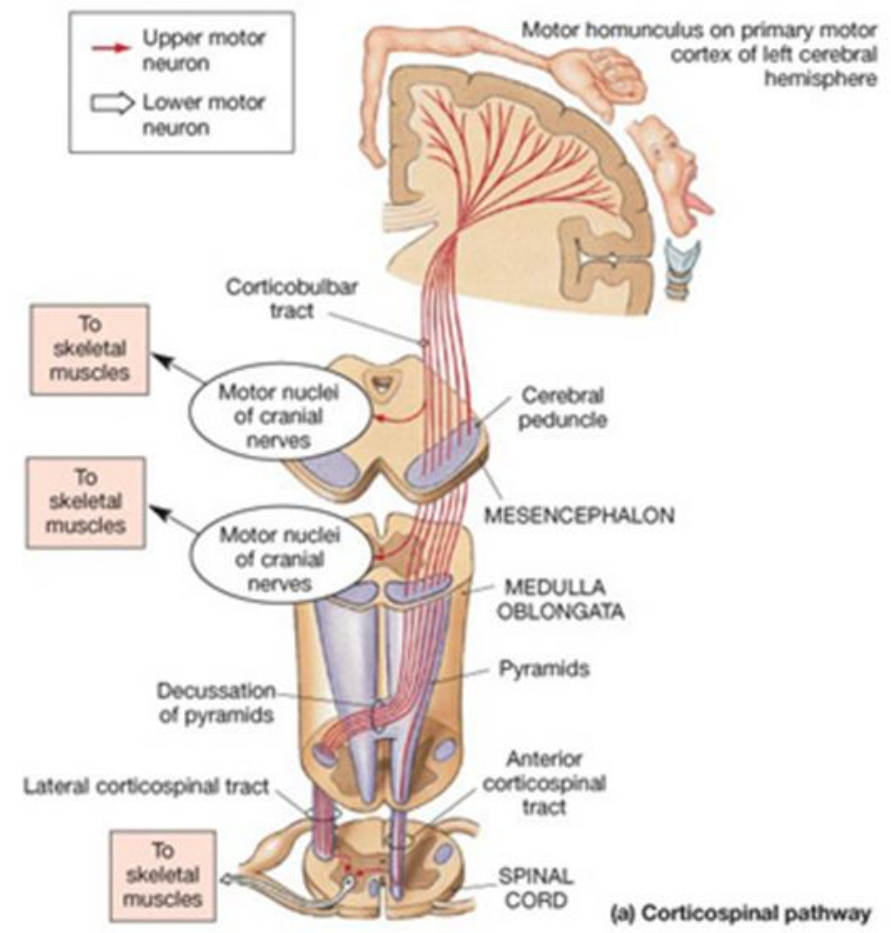

Figure2: Ref: http://brainmind.net/BrainLecture1.html 


\subsubsection{Rat Corticospinal tract}

According to Block, F. (2005) "Most corticospinal tract neurons are located in the primary motor cortex, and in the forelimb and hindlimb parts of the primary sensory cortex". As Li, X.G. et al., 1990 pointed out "Most of the primary sensory cortex is taken up Par1, which includes the whisker pad field in rat; this projects to the sensory trigeminal nuclei rather than the spinal". As Millar, M. W. 1987 mentioned "In the primary motor cortex, corticospinal neurons are located throughout layer5". Based on Li, X. G. et al., 1990 "Neurons in the forelimb area of the motor and sensory cortices project to the cervical enlargement, whereas those in the hind-limb area project to the lumber enlargement". As Millar, M. W. 1987 explained "Use of sensitive retrograde tracers has shown that corticospinal neurons are not restricted to the primary motor and sensory cortices, but are found in an area corresponding with the supplement motor area (Fr2) and in the prefrontal cortex". In a parietal cortex, they are found in the second somatosensory area (Par2) and in the posterior parietal cortex (part of par1). As Brown. L, T, 1971 explained "The cortiospinal tract of the rat decussates in the caudal medulla and runs in the base of the dorsal columns but there is ventral uncrossed tract in the ventral funiculus". A few of these fibers are unmyelinated (joostan and Gribnau, 1988). Additional minor components of the corticospinal tract have been reported in other region of the white matter (Liange et al., 1991). According to D., Tracey., 2004 "Corticospinal axons terminates in all spinal laminae contralateral to the cells of origin, with dense terminations lamina 3-7 of the dorsal horn and less dense terminations in the ventral horn". D., Tracey. 2004 also explained that "The termination of the corticospinal tract plays a role in the control of movement through its terminations in the intermediate grey matter and ventral horn". This control is exerted primarily throughout interneurons; however as D., Tracey. 2004 pointed out "recent 
anatomical evidence shows that corticospinal axons make contacts with motor neurons in the rat as they do in primates". 
A

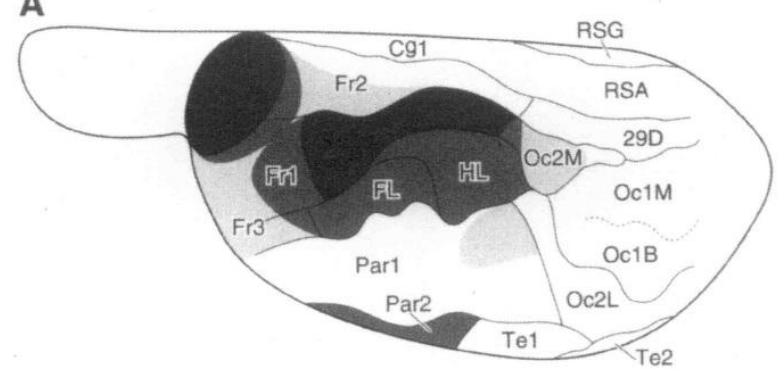

B

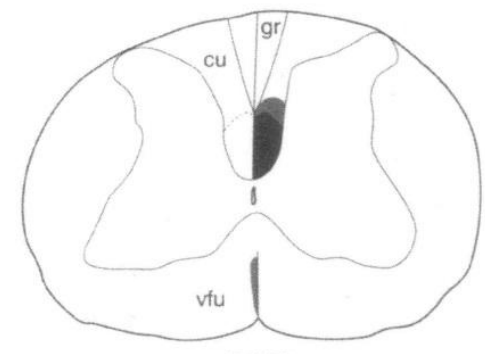

C

$\overline{0.5 \mathrm{~mm}}$

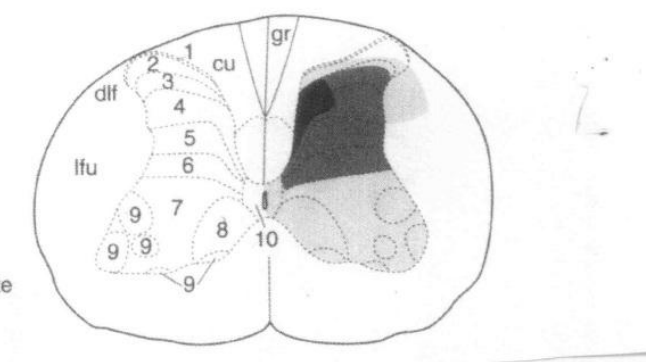

Figure3: D., Tracey. 2004 “Corticospinal tract. (A) Cells of origin (Miller, 1987) Par I + FL + HL constitute the 6rst somatosensory area, often referred to as $\mathrm{Sl}$, whereas Par2 is equivalent to the second somatosensory area, $\mathrm{SH}$. $\mathrm{Fr} \mathrm{I}+\mathrm{Fr} 3$ make up the motor cortex, whereas Fr2 corresponds to the supplementary motor area. (B) Course of corti-cospinal axons. Note the bundle of uncrossed axons in the ventral funiculus (vfu). C) Termination in the spinal cord". After George T Paxinos (1994) 


\section{Overview of Spinal cord injury}

According to Horner and Gage (2000) "Spinal cord injury is accounted as one of the devastating injuries and is mainly caused by trauma than disease". According to American spinal injury association Net "the American Spinal Injury Association (ASIA) classification published in 1982 is explained spinal cord injury is explained as different levels of ' incomplete injury' in which patients having partial damage below the neurological level When some motor and sensory function remains and 'complete injury' in which patient lose the motor and sensory function completely ". After trauma, spinal cord injury accrues in two phases the first is primary injury which is the formation of cavity and displacement and the second phase include the continue of necrotic (passive) cell death and apoptotic (programmed) cell death (Beattle, M. S. et al., 2009) which leads the sudden influx of inflammatory cells at injury site that express cytokines chemokine's causing cell damage(Fitch, MT. et al., 1997) which with the exception of olfactory sensory projections in olfactory epithelium and small pathway in the hypothalamus they are unable to regenerate(Chauvel, N. et al., 1998 ; Monti, Graziadei GA. et al., 1980). 


\subsection{The response of neuronal cell to spinal cord injury}

At the injury site, axons start degenerating and dying back, when reactive astrocytes and proteoglycan, which is described in next sections create glial scar Sofroniew M.V. (2009). Glial scar is the main barrier to axonal regeneration Sofroniew M.V. (2009). As Silver, J. et al. (2004); Ramón, Y. Cajal. (1928) described in cervical hemisection model the damaged corticospinal tract fibers produce wallerian degeneration distal to lesion area and also at proximal segments of lesion area there is retrograde die-back and axons form dystrophic endbulb close to glial scar (figure4).

Chronic study done by Li, Y. \& Raisman, G. (1998) has proven that even after 13 weeks postinjury the large varicosities at dystrophic end bulbs are still persistent, capable of sprouting and are myelinated by schawnn cells migrated to the lesion area from peripheral root entry zone. Further study by Houle J. D. (1991) at chronic lumber hemisection model at lumber level shows that dystrophic end bulb sprouts at presence of peripheral nerve implant. 


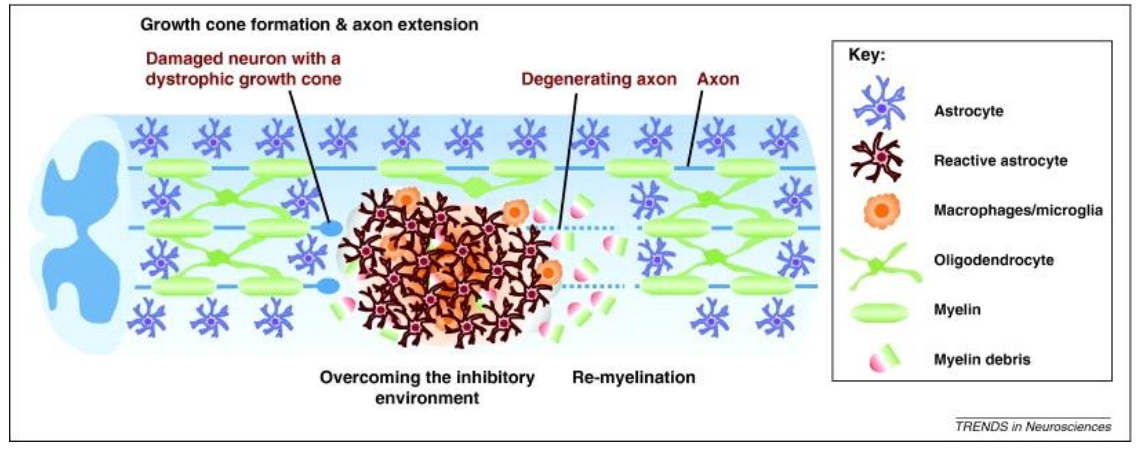

Figure 4: After Eun-Mi Hur et al., (2012) 


\subsubsection{The response of astrocytes to spinal cord injury}

\subsubsection{Astrocytes in healthy tissue}

Among glial cells, astrocytes are the most common glial cells and play the main role in CNS physiology. Astrocytes can communicate with over 100, 00 synapse terminal by releasing of glitotransmitter allowing them to play role in regulating neuronal cells in non - overlapping manner such that only the most distal domains of processes intermingle with another and therefore supply substrate for the development of gap junctions (Bushong EA et al., 2004). Astrocytes regulate the main physiological function during CNS development and adulthood. They are the main regulators of ions and water haemostasis. They are involved in neurotransmitter uptake, blood flow, construction of BBB and BSB, giving nutrition and metabolites to neurons and synaptic plasticity (Jacobson M, 1991).

\subsubsection{Glial scar and Reactive Astrogliosis}

Astrocytes play critical role in normal CNS. They go through significant molecular, functional and gene expression changes after $\mathrm{SCl}$. Based on the level of damage to spinal cord injury these alterations are causing reactive astrogliosis ( Akaoka H, et al., 2001) . In moderate reactive astrogliosis which occurs during neurotoxic injury 'isomorphic gliosis' (Sofroniew MV. et al., 2010) such as "multiple sclerosis and autoimmune inflammatory disorders" Sofroniew MV. et al., 2010, there is no significant proliferation of the astrocytes however hypertrophy can be seen which follows by increase in expression of GFAP and other intermediate filaments e.g. vimentin and cytokines such as TGF- $\beta$, IL-1 $\beta$ (Sofroniew MV. et al., 2010). As Fitch MT, et al., (2008) explained "in severe cases, there is hypertrophy 
of astrocytes cell bodies and astrocyte processes and increase in expression of intermediate filament GFAP, vimentin and nestin which forms Glial scar". Also Barres, BA.2008 said "Glial scar consists of reactive astrocytes, activated microglia, oligodendrocyte, and macrophages and glial precursors such as NG2 ". After injury reactive astrocytices' processes intermingle and form a barrier which excludes inflammatory cytokines (Barres, BA. 2003).

\subsubsection{The response of Oligodedrocytes to spinal cord injury}

During development, oligodedrocytes emerge from ventral region of ventricular zone of embryonic neural tube, oligo -specific progenitor, which also gives rise to neurones ( Lu QR., et al., 2002). From there oligodetrocytes progenitor cells (OPCs) migrate to spinal cord and form myelin- forming oligodedrocytes ( Lu QR., et al., 2002). In spinal cord each Interfascicular oligodendrocyte are aligned in rows between myelinated axons (Lu QR., et al., 2002). Each oligodetrocytes cytoplasmic process is associated with more than one myelinated axon central nervous system unlike peripheral nerve each Schwann cells which are related with only one myelinated axon in peripheral nerve (Q.Richard Lu, 2002). Satellite oligodedrocytes, the second type of oligodendrocytes, do not myelinate axons, they are found around the cell bodies of neurones and similar to astrocytes they provide micro-environment for neuronal growth ( John A. K. 2005). The third type of oligodedrocytes which do not myelinate axons join node of ranvier in white matter along with astrocytes (John A. K. 2005). According to Filbin MT., 2003 “When spinal cord injury occurs myelin breakdown produces some class of proteoglycans that are responsible for the failure of axonal regeneration". They study done by Wang, X et al. (2000) shows that"Myelin associated Glycoprotein (MAG), Myelin Associated Protein (MAP) and Nogo (three isoforms 
Nogo A, B, C) are axonal outgrowth inhibitory molecules in cell culture ". One of the mechanisms associated with protein inhibitors is the" interaction of Nogo A on oligodendrocyte surface with Nogo-66 Receptor (NgR) on axons". In adult uninjured central nervous system Nogo is expressed whereas expression of $\mathrm{NgR}$ is minimal before myelination. The juxtaposition distribution of these two proteins maintains axonal tract stability and perhaps modulates synaptic structural plasticity. (Filbin MT., 2003) After spinal cord trauma Nogo A upregulates but the NgR expression remains constant (Filbin MT., 2003). As Wang, X et al., (2000) found out the opposing distribution of these two ligandreceptors limit axonal sprouting in-vitro. 


\section{The repair of spinal cord injury}

In the field of spinal cord repair, regeneration and sprouting are two distinct terms used to define axonal repair. The understating of these growth responses helps to find out about the mechanism of repair and different approach. "Regeneration" refers to growth of cut axon or new growth axons at the tip, and normally propose transmission of growth over some distance, as Cohen, I.R et al., 2012 pointed out "e.g. spontaneous growth of peripheral nerve after injury". Also as Cohen, I.R et al., 2012 explained "Sprouting on the other hand, refers to new growth that can occur in either transected or intact axon and can happen anywhere along the length of the axon" usually over a short distance. According to mechanism underlying SCl pathology, Choya Yoon et al., (2011) have divided experimental approaches targeting axonal repair in four groups as it is mentioned in the next section.

\subsection{The placement of molecular and cellular bridge in the lesion cavity}

\subsubsection{Embryonic stem cells and induced pluripotent stem cells}

According to Li, J. et al.2012 “Embryonic stem cells (ESCs) are pluripotent, selfrenewal cell of inner cell mass fibroblast at the early embryo which is able to replicate indefinitely and differentiate to all cell types of primitive germ layer: ectoderm, mesoderm, endoderm". The studied has proven the therapeutic efficiency of ESCS and induced pluripotent stem cells (IPSCs) in repair of spinal cord. For example the intravenously transplantation of undifferentiated ESCs from mouse tail vain into T10 contused mice spinal cord shows axonal regeneration, motor function recovery and to decrease in macrophages 
and neurotrophins (Bottai et al., 2010)

\subsubsection{Mesenchymal Stem Cells (MSCs)}

As Seo, et al., 2012 explained “Mesenchymal Stem Cells (MSCs) are adult stem cells traditionally derived from bone marrow (BM)". They provide ideal culture model for the study of multipotent stem cell biology and stem cell therapy. "They might differentiate in to Mesenchymal lineages such as steoblasts, adipocytes and chondrocytes, neural cells" as Arnold I. Caplan et al., 2011 defined. They express some cytokines such as CD105, CD73 but do not express hematopoietic surface protein such as CD45, CD19 (Creative Bioarray Net). As scientists found out "in stem cell therapy the transplantation of MSCs is preferred because they are available, their isolation from cryopreservation is simple, the number of cells is clinically achievable and they are capable of reducing inhibitory molecules and promoting axon regeneration" (Li, J. et al., 2013).The study done by ( Karaoz, et al., 2012 ) on the transplant of undifferentiated MSCs in contusion rat model show the influence on some anti-inflammatory cytokines such as the down regulation of IL- 4 and IL-13 and TNF- $\alpha$ and IL-6. These changes of cytokines cause the alteration of microphage phenotype which protects more axons, creates less scar tissue and more myelin sparing. It has also confirmed motor neurones function recovery. 


\subsubsection{Neural stem cells and progenitor cells}

in spite of the advantages of using stem cell line mainly for therapeutic reasons, ethical issues such as liability to abuse human life and suffering (Julian Savulescu, 1999),triggers scientists to produce specific cell lineages such as neural stem cell/progenitor cell (NSCs/PCs), olfactory ensheathing cells, motor neurons, oligodendrocytes progenitor cells in-vitro from ESCs and IPSCs. The study of (Cui et al., 2011) in T9-T10 compression mice model compares the transplant of wild-type, based on Yi-Fang, C. et al.,2011 "substrate adherent embryonic stem cell-derived neural aggregates (SENAs) " with L1 (member of immunoglobulin subfamily) over-expressing SENAs (Appel F, 1993). The result shows that the L1 over expressing SENAs survive better three days after transplantation, and enhance locomotor function. L1 influences tissue environment by increasing "neuronal differentiation and neurite outgrowth and decreasing astrocytic differentiation" Yi-Fang, C. et al.,2011.

\subsubsection{Schwann Cells}

It has been documented that endogenous Schwann cells (SCs) migrate from proliferating ependymal cell of central canal into spinal cord contusion model and subsequently ensheath and myelinate large number of regenerated axon (Beattie et al.,1997). The molecular mechanism underlying the schwann cell migration into injury area is unknown but it can be due to" induced breakdown of glial limitans at pia surface and blood vessel " as Beattie et al.,1997 explained. Unlike OECs, Schwann cells do not intermingle with astrocytes. According to (Li. et al., 2003) astrocytes have greater affinity for OECs than Schwann cells 
and in-vitro study by Anthony N. et al., (2003) shows that Olfactory Enscheathing Cells have 2.8 tims higher possibility to co-localize with astrocytes than Schwann cells. Also as Xu et al., 1997 shows "The cultured SCs isolated from peripheral nerve graft transplanted in to lesioned optic nerve and spinal cord provides pathways for elongation of injured fibers". As reichardt L.F. (2006) found out "grafted Schwann cell produced neurotrophic factors, e.g. NGF, BDNF, and CNTF which helps the intrinsic regeneration and growth of damaged axons, and also generate different cell adhesion molecules and extracellular matrix protein such as N-CAM, L1, laminin and collagens". As Aguayo et al., (2008) observed the transplant of Schwann cell precursors (SCPs) derived from the main graft of $2 \mathrm{~d}$ post natal rats in $\mathrm{C} 4$ dorsal hemisection rats caused the improvement of axonal regeneration and remyelination, with no restoration of sensory function.

\subsubsection{Olfactory Ensheathing Cells}

Olfactory Ensheathing Cells (OECs) "are found in lamina propria of olfactory epithelium in primary olfactory system" as Jike, L. 2012 explained. Based on Marc, J. et al., (2006 ) "In nasal cavity, OECs are located in lamina propria where they are in close relation with afferent axons of olfactory receptor neurons and In the cranium, OECs are found in the first nerve layer that wraps the outer most level of cranial olfactory bulb". Also according to Marc,J. et al., 2006 "As direct exposure of olfactory sensory neurons to chemical and external environment makes them susceptible to damage primary olfactory system has the capability to regrow nerve fibers during adult hood continuously". Therefore, scientists were encouraged to examine their potential of regeneration into the CNS. As Ying Li, et al., (1998 ) explained "The OEC's potential for regeneration has been observed to repair the damaged corticospinal tract and they provide a unique feature of axonal regeneration following OECs 
transplantation into transected spinal cord". Also Ying Li, et al., (1998) emphasised "They form fibroblast-like cell (A cells) tunnel around" the myelinated ( $S$ cells) enwrapped axons to provide permissive environment for newly-formed axons (Li, et al., 1998). OEC cells are explained in more detail in section. 


\subsection{The repair of spinal cord injury with growth factor}

Many groups have studied the effect of "growth factors in injured adult spinal cord" as Lu, P. 2008 explained. In many cases lesion area has been transplanted by cellular grafts to build up bridge for axonal regeneration. As Menei, P. et al.,( 1998) described "Growth factors are delivered with techniques such as direct infusion of protein or gene delivery technique where in genes encoding growth factor are expressed by viral gene therapy vectors" . For example, according to Menei, P. et al., 1998 "the infusion of brain-derived neurotrophic factor (BDNF) and neurotrophin-3 (NT-3) at transected T8- T9 adult rat spinal cord transplanted by Schwann cells (SC) modulates motor function by promotion of brain stem neurons regeneration". It is also been observed by Choya yoon et al., 2012 that "glial cell line-derived neurotropic factor (GDNF) and fibroblast-like growth factor (FGF) stimulate axonal growth "and although the infusion of these two growth factors increase growth of nociceptive spinal axons injury, it can also cause dysfunctional sprouting and pain after $\mathrm{SCl}$ (Choya yoon et al., 2012). 


\subsection{Neutralizing inhibitors to axonal regeneration}

To avoid inhibition of axonal growth, glial scar proteoglycan inhibitors such as chondroitin sulphate proteoglycan CSPGs can be neutralized. According to Galtrey, C.M. et al. (2007) "CSPG consist of core protein and glycosaminoglycan (GAG) chains that is involved in the formation extracellular matrix ". As It has been demonstrated by Staphanie D.B. et al.,(2011) "In excess of astrocytes after injury, CSPGs produced cell adhesion control protein 42, Rho and Rac protein which are involved in the Rho-associated coiled-coil kinase (Rock) signalling pathway". Also as It is been discovered by Vinhu Sahni et al.(2010) "GSPGs are involved in the formation of glial scar through Rock signalling pathway". The study by Paul, L et al., (2007), shows that the inhibition of Rock signalling path way increases neurite outgrowth in the inhibitory chondroitin sulphate proteoglycan substrate. Bacterial enzyme chondroitinase (CHASE) degrades CSPGs and changes the inhibitory surface to permissive environment (Mckeon, R. J.et al., 1998). Also Mckeon, R. J.et al., 1998 demonstrated that "the treatment of retinal ganglion cell cultured on scar explants shows only elongation of some neurite after treatment by CHASE". 


\subsection{Combination therapy:}

It is understandable that the combination of single treatment is required to address the spinal cord injuries deficits such as molecular imbalance, fibrotic scar formation and functional deficit. The combination of strategies can either have single or multiple actions they can either "induce the growth and survival (such as neurotrophins and cyclic AMP) or reduce inhibitory factors (such as antimyelin-associated growth inhibitors and digestion of glial scar-associated inhibitors)" as discussed in (Pain \& Central Nervous System Week Net). As experiment by Vaněček V. et al., 2012 shows "the transplanted stained mesenchymal stem cells (MSC) guided by super paramagnetic iron oxide nanoparticles field " in the lesion site shows significant cell numbers and distribution compared with control animals. Moreover, the SC matrix combined with laminin and gelatine shows better Schwann cell survival, graft vascularization and growth (Salehi et al., 2009). In other study using biodegradable polymer scaffold (poly-lactic-co-glycolic acid polymer (PLGA) with seeded NSCs or SCs simplifies axonal regeneration in transacted spinal cord A. C. Flint, et al. (2001). Oslon, H.E.et al., (2009) \& Salehi et al., (2009) observed better recovery of rat hind limb motor function after cotransplantation of OECs with embryonic stem cell-derived motor neuron along other cell type groups. 


\section{Overview of Olfactory system}

\subsection{Origin}

As the study by Barraud, P. et al., (2010) in chicken embryo shows olfactory ensheathing cells (OECs) infact originate from neural crest as schwann cells do. They has similar developmental characteristic as SCs (Barraud, P. et al., 2010). During development, OEC develops from the precursor cells in olfactory epithelium which migrate from olfactory epithelium and develops processes which ensheathes neuronal axons (Chuah MI, et al., 1991). The adult neurosensory cells of primary olfactory system are able to regrow after loss by injury or turnover (Machy-sim\& Kittel, 1991). Newly formed olfactory fibres which are ensheathed by olfactory ensheathing cells that provides guidance for olfactory cross transitional zone of olfactory peripheral nervous system and CNS and synapses "with mitral cell dendrites in glomerular layer of the olfactory bulb to transduce olfactory input to the brain " as Hayat, S. (2003) explained. According to Fairless, R. et al., (2005) "Olfactory peripheral nervous system components contain olfactory mucosa, which is subdivided in to the olfactory epithelium and lamina propria (Figure 5)", also as Fairless, R. et al., (2005) “Olfactory epithelium which has olfactory receptor neurones (ORNs), project cilia into the nasal cavity, sustentacular cells (non-neuronal supporting cells), globose basal cells (putative stem cells for the epithelium), horizontal basal cells (putative stem cells) and Bowman's gland and ducts ". More over as Fairless, R. et al., (2005) mentioned "The lamina propria consists of loose connective tissue, olfactory nerve fibroblast (ONF) and olfactory ensheathing cells (OECs), which wrap around bundles of olfactory receptor neurones extending from the olfactory epithelium" and the ORN axons extend through the cribriform plate and enter the outer surface of olfactory bulb, where the fibroblastic ensheathment terminates and OEC sheaths expose to allow the fibres from different 
fascicles to attach the olfactory nerve fibres layer before going into glomeruli." 


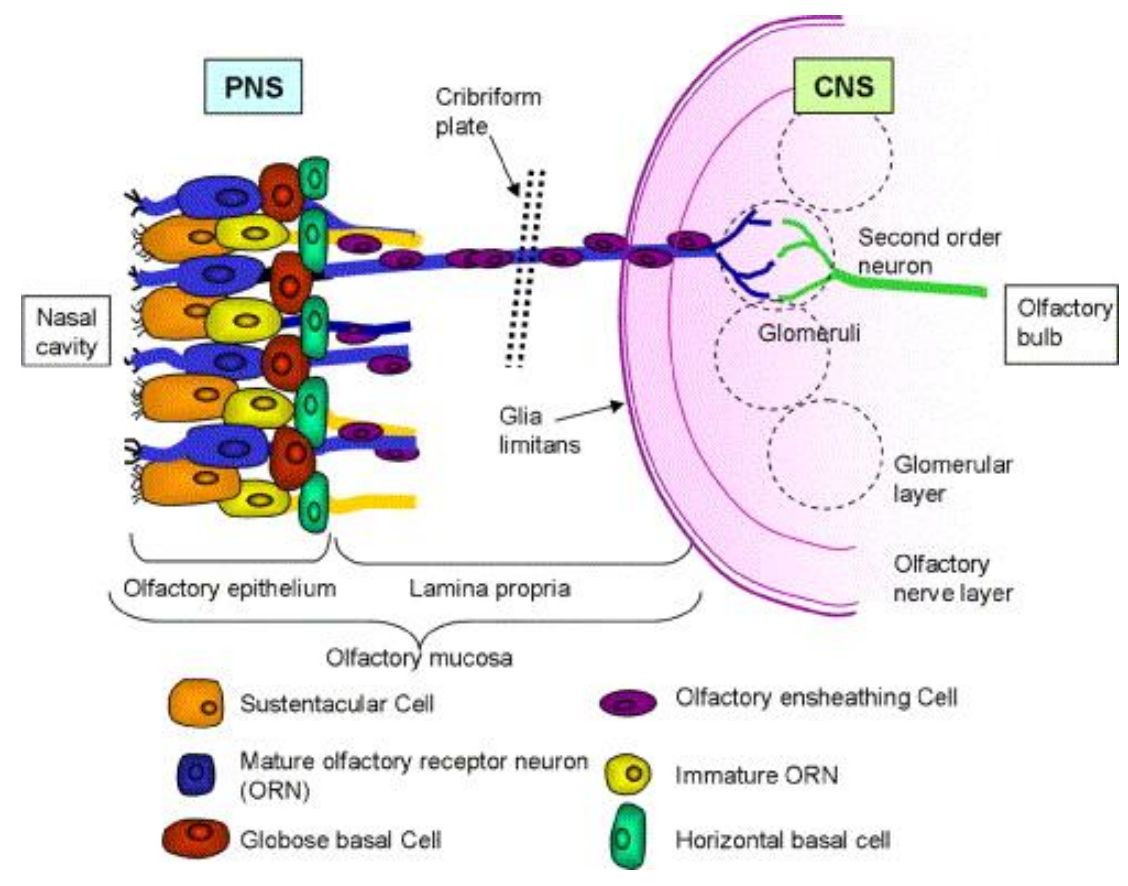

Figure 5: After Richard Fairless, (2005) 


\subsection{Characterisation}

Olfactory ensheathing cells express variety of phenotypic characteristics in both in-vivo and based on J. Gordon Boyd et al.,( 2005) " in_vitro including the ability to myelinate axons", expressing glial fibrillary acidic protein(GFAP) (Ramon-Cueto A,1992 ), S100 (Chuah MI,et al., 1993), P75 (Barnett SC,et al.,. 1993). In fact variation in expressing GFAP leads to divide OECs into two cell types, astrocyte-like glia and schwann cell-like glia (Pixley SK, 1992). The study done by (Pixley SK, 1992) in isolated OECs from new born rat olfactory mucosa shows that both two types of cells express S100 and GFAP, however as Jennifer R. et al., (2011) said "Schwann cell -like glial cells were similar to schwann cells supporting peripheral nerve due to their spindle shape morphology and $\mathrm{p} 75^{\mathrm{NTR}}$ expression, whereas astrocyte-like glial cells have denser cytoplasm surrounding their nucleus and were less abundant in cultured mucosa". As Ramon C et al., 1993 reported "the overall phenotype observed was $98.5 \%$ p75 ${ }^{\text {NTR }}$ positive". As Field PM et al., (2003) described 'OECs have an ovoid nucleus which is generally located at one age of the bundle of axons they ensheath. The basic structural principle of OECs is that they have two differentiated surface, which are structurally and functionally completely distinct: (1) smooth, rounded abaxial (i.e.,outer) surface which is uniformly and completely covered by a Basal lamina (BL), and faces the extracellular space containing ONFs and collagen fibres (PM et al., 2003). The cells is curved around so that (2) the inner process-bearing (adaxonal) surface, which has BL, encircle an axon-containing territory (PM et al., 2003). The outer, encircling processes overlap so as to complete the enclosure of the axon and the whole structure is surrounded by single continues $\mathrm{BL}$, within the inner compartment the naked axons are separated into 
interconnected territories by sheet-like inner OEC processes ( PM et al., 2003).

\subsection{Function}

As Jike Lu. (2002) explained "Olfactory escheating cells have the ability to migrate in brain possibly through blood vessels". Olfactory ensheathing cell alignment in the lesion area is similar to that of olfactory system (Ramon. C.A., 1994). Also "OECs can migrate through the host cord stump and lesion site after transplantation in transacted cord" Jike Lu. (2002). According to John P. Fraher (1999) "The study by Ramon. C.A., (1994) shows that the cut dorsal root resutured and transplanted by selectively cultured OECs has shown extensive regeneration of dorsal root axons along OECs alignment into dorsal horn where these fibres terminate". According to R.J.M. Franklin (1996) "OECs are able to myelinate demyelinated axons or damaged fibre in the lesion core in the adult rat spinal cord ". Also based on Kato T et al., 2000 The in-vivo study shows the transplant of olfactory ensheathing cells derived from adult rat olfactory bulb transplanted into lesion site, myelinates non-myelinated axon by cytoplasmic layer with large nuclei in spinal cord lesion which is schwann cell-like myelination. Furthermore, the electrophysiology study done by Imaizumi et al.,(2000), has proven the ability of transplanted OECs improve conduction velocity impulse over $1 \mathrm{~cm}$ beyond the lesion site at transacted dorsal column of rat spinal cord. This finding proves that OECs is good candidate for myeline related disease therapy such as multiple sclerosis (Feinstein, A. 2007). Also as Ni, W.F. (2010) explained " OECs secrete favourable substrates for axonal growth such as a variety of neurotrophins nerve growth factor, brain-derived neurothrophic factor, neurothrophin (NT)-3 and NT-4", "Laminin, Cell adhesion molecule 
LI, fibronectin, S100, glial-drived nexin and N-CAM" Jike Lu. (2002) which allow clinicians to use OECs against diseases such as Alzaimer disease which cause amyloid beta toxicity (Mattson, MP. 2008).

\subsection{Role of centrally derived olfactory ensheathing cells}

As it has been explained earlier in section 4.2, olfactory ensheathing cells derived olfactory bulb has shown therapeutic efficacy in experimental approach. According Radtke et al., (2012) "They provide neurotrophic support and axon guidance channel for axon regeneration, and myelination of regenerated axon in spinal cord injury to improve rapid impulse conduction". As Li et al, (2000) found out intraspinal olfactory ensheathing primary cell culture derived from olfactory bulb supports regeneration of fibres and enwrap around fascicles 'group of axons' in localised rat corticospinal tract lesion model. More over Radtke et al., (2012) explained that "myelin formation and axonal regeneration with high density of antibody nav 1.6 newly formed node of Ranvier in sciatic nerve crush lesion model transplanted by OEC". Also, Jike Lu, et al., (2002) has observed that “OECs' transplantation improve rapid conduction across the transacted dorsal columns of the rat spinal cord at T5, L2 level”. As R.H. Baloh et al., (1998) observed the stimulation of cultured OECs by growth factors, e.g. NGF, BDNF, and GDNF exerts neurotropic factors which promote neurite outgrowth in autocrine manner. 


\subsection{Role of periphery derived olfactory ensheathing cells at spine regeneration}

Although, the therapeutic property of olfactory ensheathing cells has been proven in various experimental models, the surgical procedure to harvest OEC from human olfactory bulb is not therapeutically accessible. Therefore, periphery derive OEC, Olfactory Mucosa Cell (OMCs) can be an alternative option obtained from small biopsy of lamina propria of olfactory mucosa from external nares (nostrils)(Feron, F. et al, 1998). Apart from inaccessibility, auto-transplant of OM either in solid piece of cultured cells or cultured OM which avoid problem with immunological rejection make transplant of OM more feasible for therapeutic purposes. In experimental models, OMCs show almost similar characteristic to OECs. It is immunoreactive to $\mathrm{p} 75^{\mathrm{NTR}}$ and in cultured OM cells can migrate within lamina propria. OMs show similar characteristic to those derived from Olfactory bulb (Lu J, 2002). It has high level of nerve growth factor (Shelton DI, et al, 1986) and neurotropic factors (Thoenon, H.1987) which are aligned with growing axons and allow axon elongation in distal and proximal of transection site (Shelton DI, et al, 1986). As Harsha R. Jani (2004) observed that " OM samples have higher proportion of OECs than OB and maintained 50:50 ONF/OECs ratio and the higher rate of OEC proliferation for longer period than do OB cultures". As (Yamamoto M. et al., 2009) found out the OMs transplant in unilateral CST lesion model did not cause any regenerating axons but restore directed for pa-reaching (DFR). Therefore as Yamamoto M. et al., 2009 said "it is thought that the recovery can be due to any other function such as sprouting of damaged or undamaged axons". 


\subsection{Clinical aspects of olfactory ensheathing cells transplantation}

According to Wang, Ying, et al., (2012) "Over the last decades various experimental therapeutic approaches has been discovered to promote the regrow and regeneration of damaged axons". Intraspinal transplantation of non -neuronal cells among those OECs have proven the potential to restore damaged neuronal pathway. Clinical studies of OECs have shown dissimilar results. Recent clinical study by Yaojian Rao et al., (2013) to investigate the therapeutic efficacy of OECs auto-graft to repair cervical spinal cord damage in 8 patients have shown significant improvement in motor function and sensation recovery 3 months post operative, however there was not substantial recovery by 1 year after operation. More study done by Tabakow, P. et al., (2013) at three patients with chronic thoracic paraplegia shows that transplanted autologous cultured OM in two patients has caused improvement in ASIA A to ASIA C score after the first three months with regeneration of some white matter tract pathways, the third patient however remains ASIA A with sensory and motor improvement of only one segment below the injured spinal cord and no further significant improvement was observed by the end of one year post operation. Both studies did not show any side effect of inflammation such as neuropathic pain, neuroinfection and tumorigenesis in transplanted patients after one year. 


\section{Objective:}

1. Xenotransplant of olfactory ensheathing cells derived olfactory bulb as an alternative source to repair spinal cord damage

2. To find out the effect of an immune attack on the grafted tissue To find out if the rejection mouse xenograft would change directed paw reaching

3. recovery in transplanted rat after stopping the injected of immunosuppressant agent 'cyclosporine' 


\section{Chapter 2:}

\section{Material and Method}

1. Developing complete unilateral lesions

1.1 Surgical procedure

1.2 Perfusion for cryostat sectioning

1.3 Histology to assess the size of the lesion

1.4 Histology to study the complete corticospinal tract lesion

2. Behavioural Investigation

2.1 Behavioural study before lesion making

2.2 Behavioural investigation after making the lesion and transplantation

2.3 Video recording

3. Delayed repair of complete corticospinal tract lesions by xeno-transplantation of OECS

3.1 Culture of Olfactory ensheathing cells from olfactory bulb

3.2 OEC cell suspension preparation

3.3 The microtransplantaion procedure

3.4 OECs culture histology

3.5 Tissue preparation and immunohistochemistry

4. The study of immunorejection against OEC xenotransplant

5. The study of fibrotic scar at the long term lesion animals 


\section{Developing complete unilateral lesions}

\subsection{Surgical procedure}

The first stage of the procedure was to build up constant and reproducible unilateral corticospinal tract lesion animal model using radio-frequency lesion generator (Lesion generator mode, REG-3C RF, Burlington, Mass,USA)( Figure 7). To produce complete loss of directed forepaw retrieval (DFR) on one side, the lesion has to destroy all CST and some part of grey matter (Mie Yamamoto, 2009). The procedure was done base on the study of Ying Li et al., (1994). 93 adult female rats (180-210 g body weight) of a locally inbred Albino Swiss Strain (AS) were used and all the procedure performed under UK Home Office regulation and the animal (Scientific Procedures) Act 1986. The pretrained rats were shaved and the skin were cleaned by Tamodine wound cleanser ( Vetark profrtional, Uk) at neck area and anaesthetised under a low concentration of isoflurane (1.5 or $2 \%$, Primal company) and as Ying Li., et al., (1994) “ Anaesthetised rats were mounted in stereotaxic frame with the neck flexed and the head stabilized using ear plugs and an incisor bar". Anaesthesia was adequately maintained with isoflurane-in oxygen on the anaesthesia system. According To Emmett, C.J. (1990) "During the whole procedure, the head of the animal was located rigidly in a stereotaxic apparatus in the right position (incisor bar $5 \mathrm{~mm}$ above the interaural line)" also as Naghmeh K.F. et al.,( 2003) explained "The dorsal surface of the spinal cord at the level of the first and second cervical segments were exposed through the middle line incision of the skin, separating the supraspinal muscles in midline". After locating the Occipital bone, the atlanto-occipital membrane was incised. The cervical atlas and cervical axis was opened and try to hold two segments apart by small needle. The dura matter was torn up with micro dissecting tweezers and cerebral spinal fluid (CFS) was come out. The 
presence of the median sagittal venous pattern can be the indicator of middle line, however it is not absolutely reliable and may cause some error at lesion position. The KCTE-TC-S electrode (Cosman, Germany) (figure 6) as Ying Li., 1994 explained "with a straight RF tip of $0.25 \mathrm{~mm}$ diameter and $1.8 \mathrm{~mm}$ tip length was inserted to a depth of $1.5-2 \mathrm{~mm}$ at a point of $0.5 \mathrm{~mm}$ lateral to midline". As the electrode has a built-in thermocouple (TC) temperature sensor, we set the tip temperature at $60^{\circ} \mathrm{C}$ then insert the electrode after the tip temperature reach to $60^{\circ} \mathrm{C}$, lesion was made for 30 second. The electrode was withdrawn gently. The animal supraspinal muscles and outer most layer of skin was sutured by violet braided absorbable suture ( Ethicon,Belgium). As Ann Wu., (2009) explained "After operation the animals were housed separately and maintained on a heating mat during the recovery period". Also based on Ann Wu., 2011 "Analgesic (0.025 ml of Carprofen, 50 $\mathrm{mg} / \mathrm{ml}$, s.c.) were administered daily for the first 3 days post-operatively the lesion size was dependent on two parameters, tip temperature and time". We have done the experimental procedure in 50 animals changing the tip temperature ranging from $30-80^{\circ} \mathrm{C}$ and time of 10- 60 second. Operated rats were under care and prescription of $0.0192 \mathrm{mls}$ analgesia drug Carprieve 5\% w/v (Norbrook,uk) subcutaneously for three days. The histological analysis and behaviour test proved us the consistent lesion size with the knock out function at $60^{\circ} \mathrm{C}$ tip tem and $30 \mathrm{sec}$ lesion time. 

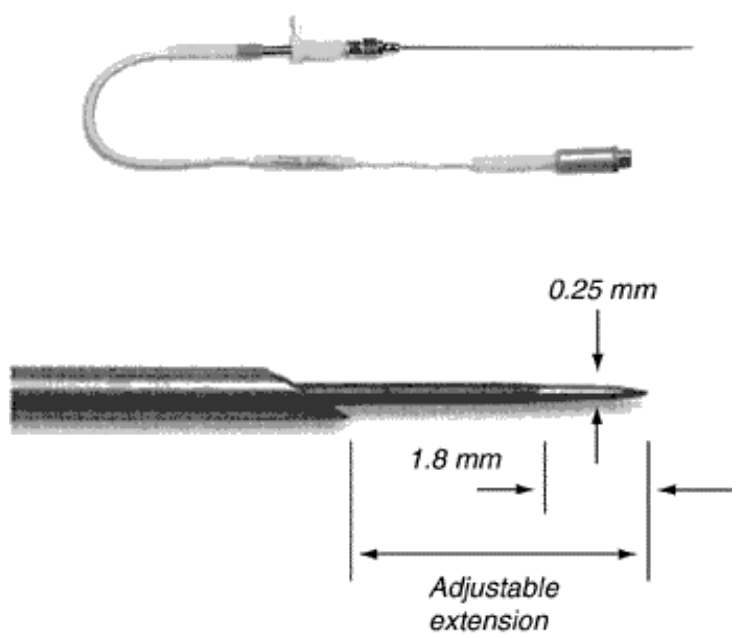

Figure 6: KCTE-TC-S electrode with a straight RF tip. Used Electrosurgical Unit - Cosman - Cordotomy Electrod kit-LCE 


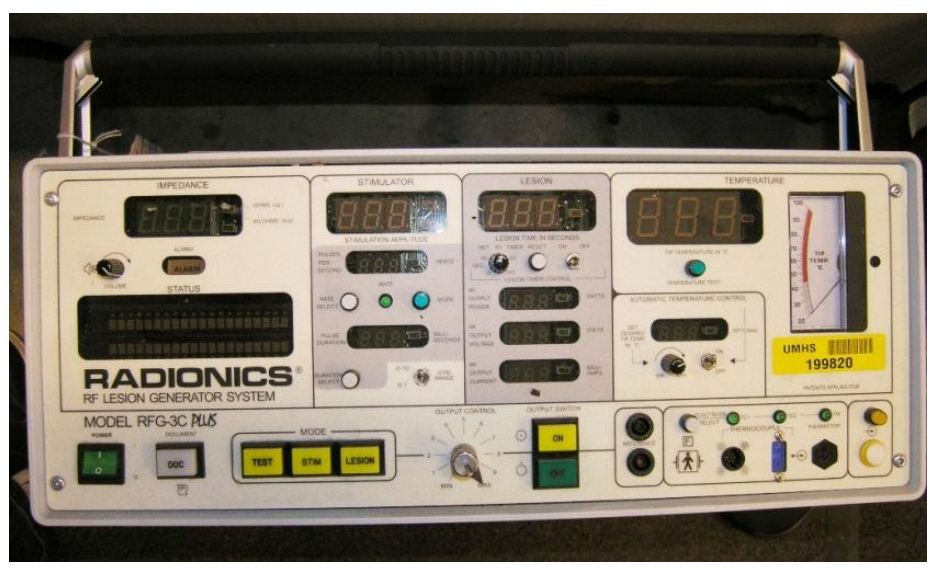

Figure7: Radionics RF Lesion Generator System, model 3Cpulse, Burlington, Germany 


\subsection{Perfusion for cryostat sectioning}

2 weeks after surgery, the animal is deeply anesthetized by $\mathrm{CO} 2$ chamber. We place the animal on its back. Spread the forelimbs. The sternum is clamped by haemostatic forceps. "Thoracotomy is done by sharp scissors to cut diaphragm laterally on both sides and cut toward the head across ribs and parallel to lungs" based on Perfusion protocol. Net. Clamp the descending aorta located along the spinal column. Use the sharp scissor to cut right atrium first then the left ventricle. $100 \mathrm{ml}$ syringe is used to inject $100 \mathrm{ml}$ PBS (0.1 M phosphate-buffered saline) to clear up blood vessels and open up the capillaries and wash the erythrocytes out of the tissue. Insert the cannula from right atrium right through the left ventricle to pass the aorta. Then switch to fixative, inject $100 \mathrm{ml}$ of $4 \%$ PFA (paraformaldehyde). To avoid the fixation of main capillaries $300 \mathrm{cc}$ of fixative was allowed to run for $\mathbf{4 0}$ minutes. The spinal cord at cervical level is exposed after perfusion, the tissue at cervical 1 and 2 is dissected out and sink the sample in $10 \%$ sucrose then $20 \%$ over the night to avoid crystal formation after freezing. According to, TAAB Laboratory and microscopy. Net "Next day the tissue is placed on $25 \mathrm{~mm}$ diameter aluminium planchette frozen by freezing spray (TAAB Laboratories Equipment Ltd, UK) and embedded by Compound for Frozen Tissue (OCT) (TAAB Laboratories Equipment Ltd, UK) on steel chuck and cut the sections by Cryostat machine (Leica CM3050, Germany) between $16 \mu-20 \mu$ and mounted on X-tra Adhesive precleaned coated micro slides (Leica microsystems, Uk)". 


\subsection{Histology to study the size of lesion}

24 As adult rats were chosen in 5 groups in which they went under operation to choose the parameters for making the reparative and consistent lesion, the surgery was performed as explained in section 1.1. The tip temperature was set at $60^{\circ} \mathrm{C}$; lesion depth $1.5 \mathrm{~mm}$, the electrode impedance remained constant at $1.4 \mathrm{~K} \Omega$. According to Ching-Yi Lin., 2011“ Animals were divided in 5 groups based on the lesion time in $20 \mathrm{sec}, 30 \mathrm{sec}, 40 \mathrm{sec}, 50 \mathrm{sec}$ and $60 \mathrm{sec}^{\prime \prime}$. The animal was perfused and the tissue was cut into $20 \mu$ horizontal sections as it were explained in section 1.2 and were examined by light microscopy. The sections were visualised by thionin staining. The right lesion time was chosen based of the size of lesion and DFR retrieving test. The sections were fixed for $10 \mathrm{~min}$ at $96 \%$ alcohol, then rehydrated by leaving for $2 \mathrm{~min}$ at $70 \%$ alcohol, $50 \%$ alcohol, distilled water respectively and stained by thionin. Finally before being incubated in Histoclear and mounted with DPX (LAMB, East Sussex, Uk), the sections washed up in distilled water and went through dehydration process by leaving in distilled water, $50 \%$ alcohol, $70 \%$ alcohol and $100 \%$ for 2 minute at each step. The result of histology and Pa retrieving behaviour assessment confirmed that $60^{\circ} \mathrm{C}$ tip temperature for a period of $30 \mathrm{sec}$ is required to destroy corticospinal tract and relevant area of grey matter unilaterally. 


\subsection{Immunohistochemistry of complete corticospinal tract lesion}

The lesion area was studied by immunohistochemistry technique looking at axons, astrocyte scar tissue and myelination. Neurofilament staining (abcam,Cambridge, Uk) was performed to check if all the axons were destroyed at one side, anti-Glial Fibrillary Acidic protein Clone GA5 (Chemicon, Uk) to look at astrocyte behaviour after lesion in corticospinal tract, Myelin Protein Zero Antibody-Neuronal Marker PO (Novus Biological, Uk) to stain peripheral type myelination in lesion area. Animal were perfused and tissue was cut as explained in section 1.2. In each case $16 \mu$ cryostat sections were fixed in $4 \%$ PFA for 30 minutes. According to Trinh, Victoria T., et al., 2013 "Sections were blocked in 2\% milk-PBS in 1\% Triton for 30 minutes and then incubated in 1/500 primary antibody of monoclonal anti-neurofilament, anti-GFAP, anti-P0 at $4^{\circ} \mathrm{C}^{\prime}$. Also based on Kenta, W., 2007 "All primary antibodies were diluted at $2 \%$ milk-PBS with $1 \%$ Triton for 2 hours at room temperature and the day after the slides were washed in PBS for 30 minutes and covered in 1/500 diluted biotynilted antimouse secondary antibody (Alexa Fluor 546 Goat anti-mouse) for all three antibodies". The sections were mounted by Fluoromount mounting media (Sigma,Uk). Immunohistochemistry analysis confirmed that the axons were destroyed at completed lesion, astrocytes proliferate around the lesion core and there were no astrocyte in the lesion epicentre, also peripheral type myelinated can be seen around the lesion centre and peripheral root. 


\section{Behavioural Investigation}

\subsection{Pre-operative ipsilateral paw reaching training}

Here we use preclinical animal model to assess forelimb activity, impairment and recovery by training rats for (reach-to -eat) ability (Whishaw, I.Q. et al, 1990) (figure 8). According to skilled pa reaching in the rat. Net "AS Female adult rats body weight of (180-200 g) were introduced to testing cage containing the slot through which they can reach food pellets". The cage was made of clear Plexiglas Perspex and $25 \times 35 \times 30 \mathrm{~cm}$ in size. Each slit is about 15 centimetres above the cage base, $2 \mathrm{~cm}$ in weight and $3 \mathrm{~cm}$ in length. Animals were trained by presentation of fragments of noodles for two days before start training . After they were feed by forceps to reach food pellets (Dried spaghetti) four times a week during two weeks prior to surgery until they learn how to reach by both forehands (forepaw). The results were recorded for 50 times of pa retrieval (locating the food advancing the lime, grasping the noodle; bring the food to the mouth and returning to the start point). Those rats with the record of both paw reaching no less than 15 times each pa were chosen for CST lesion operation. In general, after skilled forelimb reaching, the total number of 93 AS rats were able to use both pa to reach the noodle and therefore ready to go under CST lesion operation. 


\subsection{CST lesion post- operative skilled forepaw reaching assessment}

The CST lesion procedure was done on 93 pertained rats as explained in (section 1.1). Three days after surgery those operated rats recovered from surgery and had shown no abnormalities were assessed for pa reaching task 50 times three times a week for the period of 4 weeks. The movement of each pa was scored as retrieval if the limb was advanced directly through the slot towards the pellet, even though no grasping was done. The complete lesion with paw knocked out function was determined if no retrieval was recorded by the limb of operated CST lesion. By the end of 4 weeks if the knocked out limb has not shown any retrieval, the animals were going under the second operation of olfactory ensheathing cell transplantation. In total 20 rats have shown complete lesion and function deficit on operated CST lesion side. 


\subsection{Video recording}

The reaching act is filmed according to Globalmediapro.Net "by a Sony HXR-NX5 HD camcorder based on the AVCHD with a high shutter speed $(1,000 \mathrm{f} / \mathrm{sec})$ from number of perspectives" and as Naghmeh K.F., 2003 explained "The reaching act is then replayed using frame by frame replay and the movements are described in the accompanying video". 


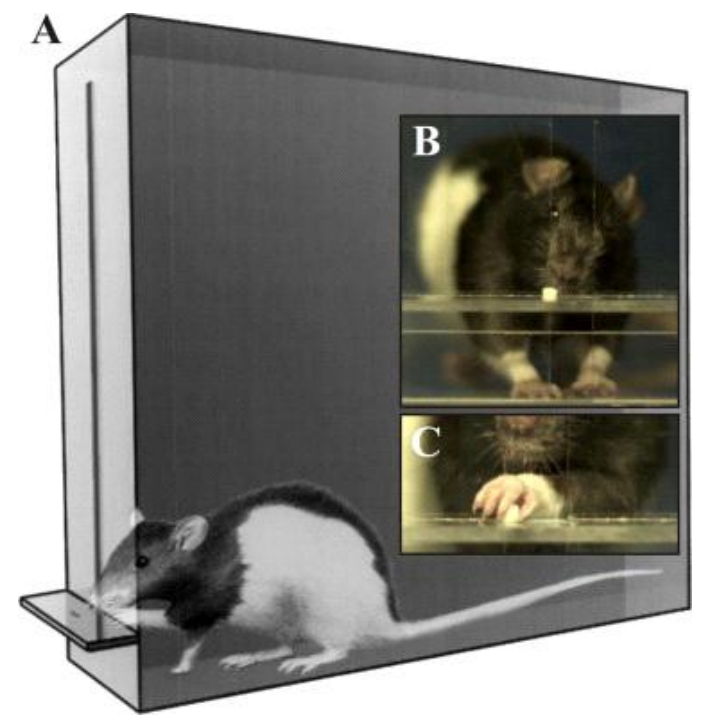

Figure8: After Metz and Whishaw (2000) 


\section{Delayed repair of complete corticospinal tract lesions by xeno- transplantation of OECs}

\subsection{Culture of Olfactory ensheathing cells from olfactory bulb}

The instruments were autoclaved by and left in flow hood. Growing media was made by (50:50) DMEM/F12 ( Invitrogen, Uk) media with penicillin $\mathrm{p} / \mathrm{s}$ and $10 \%$ foetal calf serum (FCS) and left with few dishes of hank in the cold plate in flow hood. Animal were placed under terminal anaesthesia and decapitate by $\mathrm{CO} 2$ chamber. According to Jun Wu. et al., 2008 "The olfactory bulb was dissected out and placed in a $60 \mathrm{~mm}$ dish containing hanks (HBSS) (life Technologies, Uk)". Under dissecting microscope as much of the meninges and cartilage were removed as possible using no 5 tweezers. The glomeruli were dissected out from the olfactory bulbs by slicing the bulbs in half down the centre. As Sinead M. G., et al, 2009 explained "Using small blue curved tweezers and a scalpel, white matter was removed and the tissue was washed gently in hanks and transferred into $15 \mathrm{ml}$ tube with $2 \mathrm{ml}$ of hanks with $200 \mu \mathrm{l}$ of $1 \%$ of $25 \%$ Trypsin-EDTA (Worthington, UK) and left in oven at $\left(37^{\circ} \mathrm{C}, 5 \%\right.$ CO2) for 15 mins". After trypsinization, $10 \mathrm{ml}$ of growing medium was added to stop trypsinization process. After the tissue was settled, the media was removed and only $1.5 \mathrm{ml}$ media in bottom and $2 \mu$ l of DNAse ( Invitrogen, Uk) solution was added and triturated by pipette tip until no big lumps remained. More media was added and if there were any lumps at bottom, cell suspension transferred to fresh tube spined at $1200 \mathrm{rpm}$ for 5 mins, supernant removed and $2 \mathrm{ml}$ of medium was re-suspended and plated them down on PdL coated dishes. Cultures are fed and medium is changed after 4-5 days and thereafter every 2-3 days for 16-18 days. 


\subsection{OEC cell suspension preparation}

On a day of injection, samples were washed off by hanks (HBSS) to remove any Ca2+ and mg+ trypsin by $1 \%$ of $25 \%$ Trypsin-EDTA. Then based on Emmett, C.J. et al., 1990 "incubated for 5 mins at $\left(37^{\circ} \mathrm{C}, 5 \% \mathrm{CO} 2\right)$ until most of cells are rounded and floated off the surface of the flask. At this point, $10 \mathrm{ml}$ of growing medium was added to stop trypsinization process". The cell suspension was washed twice, centrifuged at $1200 \mathrm{rpm}$ for 5 mins. Samples were washed and re-suspend in $200 \mu \mathrm{l}$ of media DMEM/F12 solution with no FCS. As foetal calf serum is immunorejected by rat immune system. Emmett, C.J. et al., 1990 explained "before transplanting cells suspension, $2 \mu$ l of DNAse was added to cleave the sticky DNA released from dying cells thus reduced further aggregation".

\subsection{The microtransplantaion procedure}

According to Emmett et al., 1990 "10 rats had shown complete absence of DFR for 8 weeks after lesion were anaesthetised and the head of the animal was located in stereotaxic apparatus at the same position as it set for lesioning, a solenoid-controlled air pressure device ( Applied Electrotnic Itd, Uk) was used to inject $5 \mu$ l of suspended OECs cells via a glass micropipette (100-150 $\mu \mathrm{m}$ tip) into the lesion site" and a midline incision was made along the length of neck". Micropipette were inserted unilaterally in the lesion side, although the scar tissue was good indicator it was hard to inject cells at lesion centre. As Naghmeh K.F., et al., 2003 explained "Immediately before implantation $5 \mu$ l of the suspension of cells were loaded into the open end of a glass capillary and once a sufficient volume of suspension was taken up, NV2 was closed, the micropipette lowered slowly until 
its tip lay at the depth of $2 \mathrm{~mm}$, Valve NVI was opened and $5 \mu \mathrm{l}$ of cells were injected at two times by pulse generator( figure 10)". By injecting $2.5 \mu$ of cells the tip was lifted up to 1 $\mathrm{mm}$ of surface of spinal cord, then the remaining of cells were injected until the cells make a bridge along of lesion length. Based on Ying. Li., et al., 1998 "The movement of liquid down the bore of the micropipette was monitored by observation of its meniscus through a microsurgery microscope (Carl Zeiss, Uk)( $\times 7$ magnification) and once $5 \mathrm{ml}$ had been injected, the stimulator was switched off, the micropipette was left in position then very slowly withdrawn from spinal cord and the skin was sutured ". The rat given subcutaneous injection of analgesic $0.025 \mathrm{ml}$ of $5 \%$ Carprofen ( ADWIA Pharmaceuticals Co, Uk) and cyclosporine (Sandimume Co, Bulingame) $100 \mathrm{ml}$ of a dosage of $6 \mathrm{mg} / \mathrm{kg} /$ day (Choi, D., et al., 2003). 


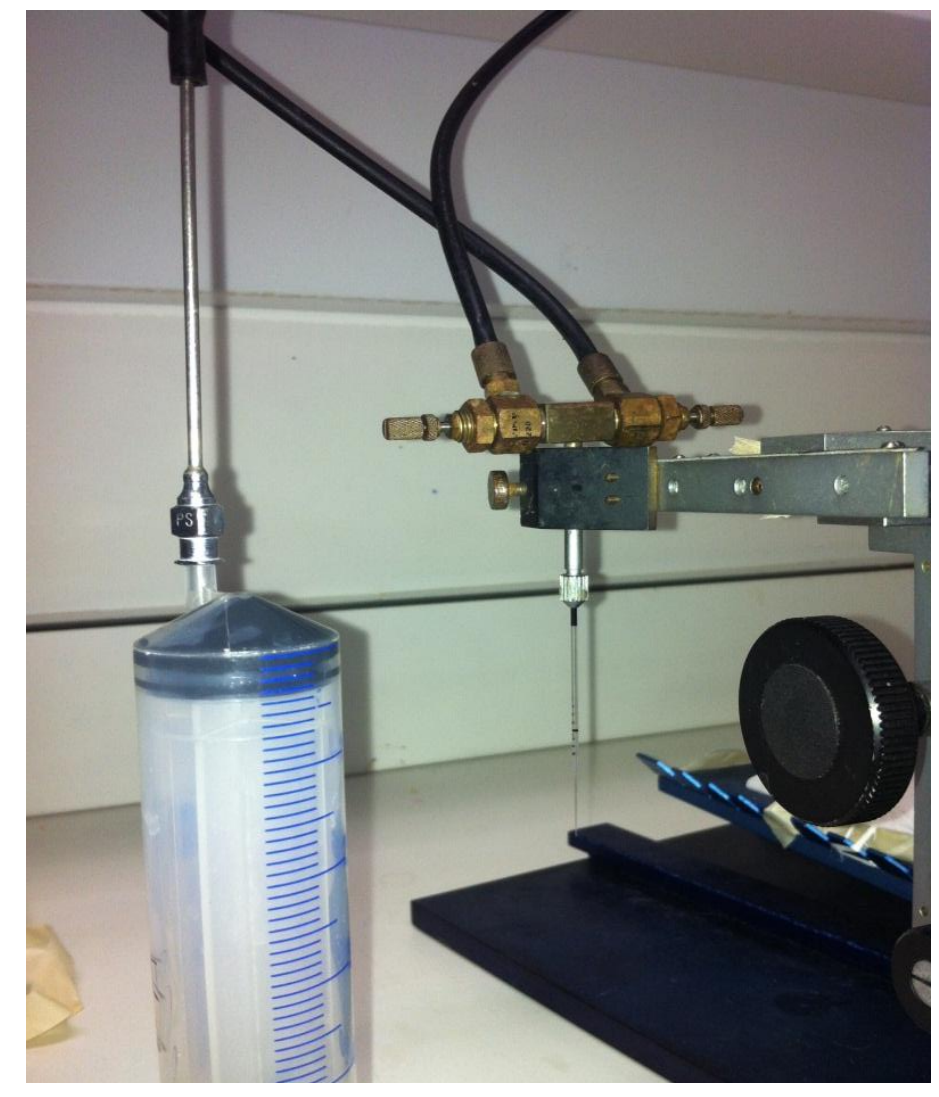

Figure 9: After Applied Electronic Itd, Uk "micropipette was front-filled by lowering its tip into this suspension, closing needle valve NV1, opening NV2 and applying suction to the micropipette via a $60 \mathrm{ml}$ plastic syringe". 


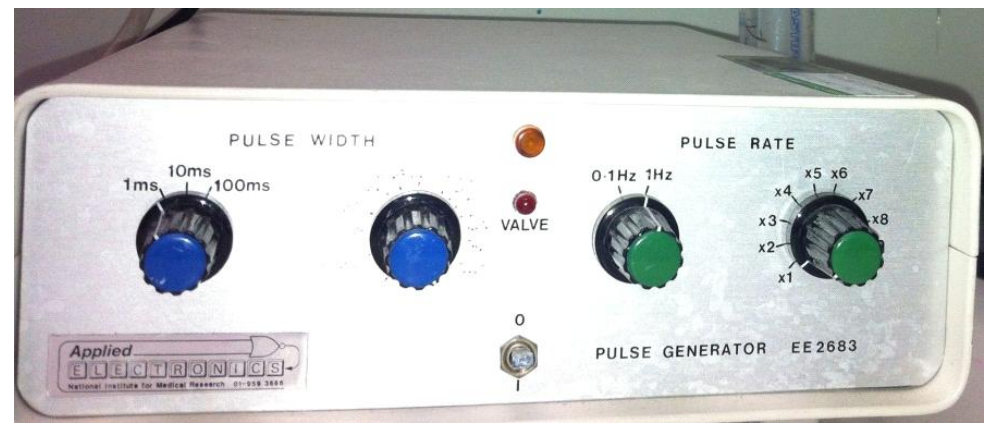

Figure10: After Applied electronic Itd, Uk "The width of the pressure pulses and the interval between them was controlled by pulse generator (Applied electronic Itd, Uk). These parameters were altered to suit variations in the cell suspension and in micropipette dimensions. Injection took approximately 4 min, commonly with a pulse length of $20 \mathrm{~ms}$, a pulse interval of $1 \mathrm{~ms}$ and a delivery pressure of 20lbfjin. With such settings, slight downward movement of the meniscus could be observed with each pulse of air. Failure in meniscus movement was corrected by stepwise increase in pulse length or air pressure". 


\subsection{OECs culture histology}

According to Ying Li., et al., 1998 "After 16-18 days, the cultured cells had segregated into two major cell types: Schwann cell like and fibroblast cell like". In order to show what type of cells had been transplanted into lesioned rats two different antibodies were used. After transplantation, a sample of the cells suspension was plated out in $35 \mathrm{~mm}$ culture dishes ( Sigma,USA) coated with Pdl with $1.5 \mathrm{ml}$ DMEMF and cultured for one day to check if OECs were still viable. Based on Vroemen, M. 2003 "A suitable cell surface antigen to select SCs is the p75 (low affinity nerve growth factor-receptor), which is widely expressed on SCs in vitro but not on fibroblast". The cells were stained for P75 ( Abcam, UK) ,Fibronectin ( Abcam, uk) and S100 ( Abcam, Uk). As Zihlmann, K.B.et al., 2005 “Cells were washed with 0.1 M PBS (PH: 7.4), fixed for 30 mins in 4\% PFA, blocked with $0.2 \%$ milk at room temperature. Then the cells were incubated with anti-p75 antibody (1/100 dilution) and fibronectin $(1 / 1000$ dilution) with $0.1 \%$ Triton at $4{ }^{\circ} \mathrm{C}$ over night and the following day, after washes in PBS, cells were incubated with Alexa anti-mouse (p75, green) (Molecular probes, Eugene, Oregon,USA, 488 wave length) and Alexa anti-rabbit (FN, red) (1/400, Molecular probes, Eugene, Oregon, USA, $568 \mathrm{~nm}$ wave length) for one hour at room temperature". According To Yin Li., et al., 1998 "After final washes in PBS the cell culture was then counterstained with $1 / 500$ of $1 \mu \mathrm{g} / \mathrm{ml}$ stock solution solution DAPI (4, 6-diaminio-2 phenylindole, dihydrochloride) (Molecular probes, Eugene, Oregon, USA, $461 \mathrm{~nm}$, wave length)". Then culture dish was washed with PBS, cover slipped with aqueous medium and viewed by confocal microscope (Leica, Uk). 


\subsection{Tissue preparation and immunohistochemistry}

Animal were perfused and $16 \mu$ sections were cut by cryostat in coronal and horizontal as explained in section 3.1. Anti-Neurofilament (Abcam,Cambridge, Uk) was performed to identify axons . Anti-Glial Fibrillary Acidic protein clone GA5 (Chemicon, Uk) to stain astrocyte around grafted area, Myelin Protein Zero Antibody-Neuronal Marker PO (Novus Biological, Uk) were used to stain peripheral type myelination in lesion area. Immunohistochemistry technique was performed as explained in section 3.1.

\subsection{The study of immunorejection against OEC xenotransplant}

In order to study whether there is any immunorejection against OECs xenotransplant at grafted tissue, we divided 15 adult female rats (180-210 g body weight) of a locally inbred Albino Swiss Strain (AS) in 5 groups. OCEs labelled by green fluorescent protein (GFP) as explained in section 3.1. The operation was performed as it discussed earlier at section 3.3. Animal was perfused and tissue was prepared as explained in section 1.2. Animals were divided in 5 groups with the survival time of 4 days, 1 week, 2 weeks, 3 weeks, 4 weeks, 5 weeks for group $1(n=2)$, group $2(n=2)$, group $3(n=4)$, group $4(n=4)$ and group5 $(n=3)$ respectively. To study the immunorejection of the grafted tissue at all groups the sections were stained by Hematoxylin \& Eosin (H\&E). To look at the GFP labeled OECs cells, sections were counterstained by Sytox Orange (Invitrogen, Uk) and viewed by confocal microscope. According to Naghmeh K.f., et al., 2003 "Slides were overstained in hematoxylin first to ensure saturation of chemical binding sites and excess staining is then removed by controlled leaching in an alcoholic acid solution (differentiation)". Leaching of the stain is arrested to a basic environment (20 sec) in Ammonia solution) whereby the stain 
becomes blue and is permanently fixed to cell structure. Finally sectioned were counterstained by eosin and mounted by DPX after dehydration. The result shows surviving transplant cells only at group 1 and 2 where the animal survival time was 1 week and 2 weeks respectively. No GFP labelled OEC could be observed at group 2, 3, and 5 where the survival time is over 2 weeks. Therefore the results prove that the animals need to be under immunosuppressant reagent after xeno-transplantation by mouse OECs in order to avoid immune rejection by leaving the animals under trial over 2 weeks time.

\subsection{The study of fibrotic scar at the long term lesion animal}

5 adult female rats (180-210 g body weight) of a locally inbred Albino Swiss Strain (AS) were lesioned as explained in section 1.1 and kept as control for the period of one year to study fibrotic scar. The directed forepaw reaching (DFR) was counted once a week. Animal were perfused and tissue were prepared and cut coronally and horizontally as explained in section 1.2. Immunohistochemistry staining was performed as explained in section 1.3. Poly clonal rabbit anti-human Fibronectin (Dako, Uk), was used to stain fibronectin and anti-Glial Fibrillary Acidic protein clone GA5 (Chemicon, Uk) was used to study astrocyte behaviour. 


\section{Chapter 3}

\section{Result}

1. Histology images to assess the lesion size before transplantation

2. The result of histology images of grafted tissue

2.1 Histology images of the effect of immune attack on the grafted tissue without the injection of immunosuppressant agent

2.2 Histology images of transplanted olfactory ensheathing cells in displaced position after injection of immunosuppressant agent

2.3 Histology images of xenotransplanted olfactory ensheathing cells in complete corticospinal tract lesion after the injection of immunosuppressant agent

\subsection{Transplant}

3. The result of Behaviour test result

3.1 The immunohistochemitry images of long term untransplanted lesion control and behaviour test results 


\section{Histology images to assess the lesion size before transplantation}
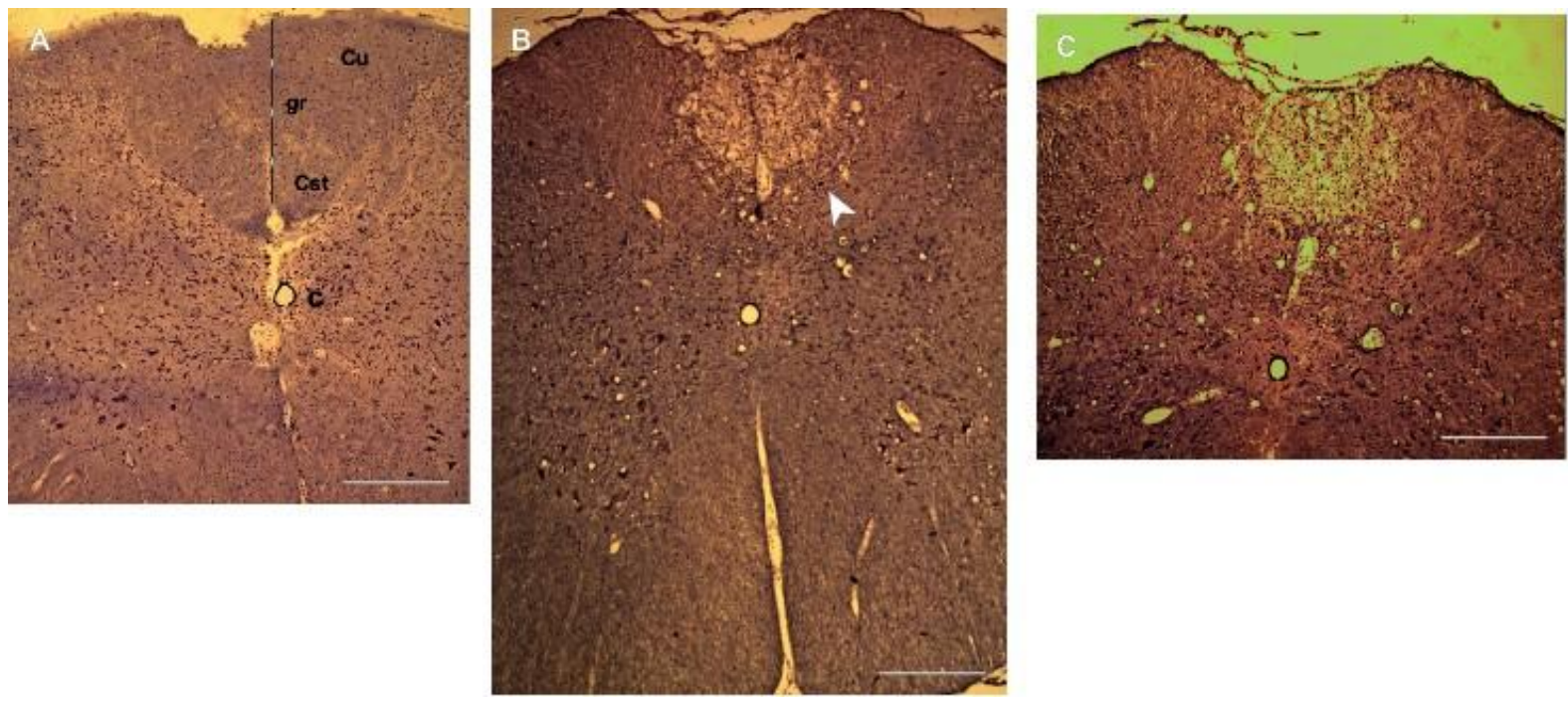

Figure1. A. $20 \mu \mathrm{m}$ coronal section of the whole spinal cord before causing lesion was stained with thionine. C, Central canal; CST, intact right corticospinal tract, (outline); cu, and gr, cuneate and gracile tracts; and midline (dashed line). Survival time: 4 weeks, scale bar: $100 \mu \mathrm{m}$, B. Destruction of the right corticospinal tract (arrow) which has spread to the left; C. The enlarged view of CST lesion; Survival time: 3 months, scale bar: 200 $\mu \mathrm{m} ; 10 \mu \mathrm{m} ; 100 \mu \mathrm{m}$. 

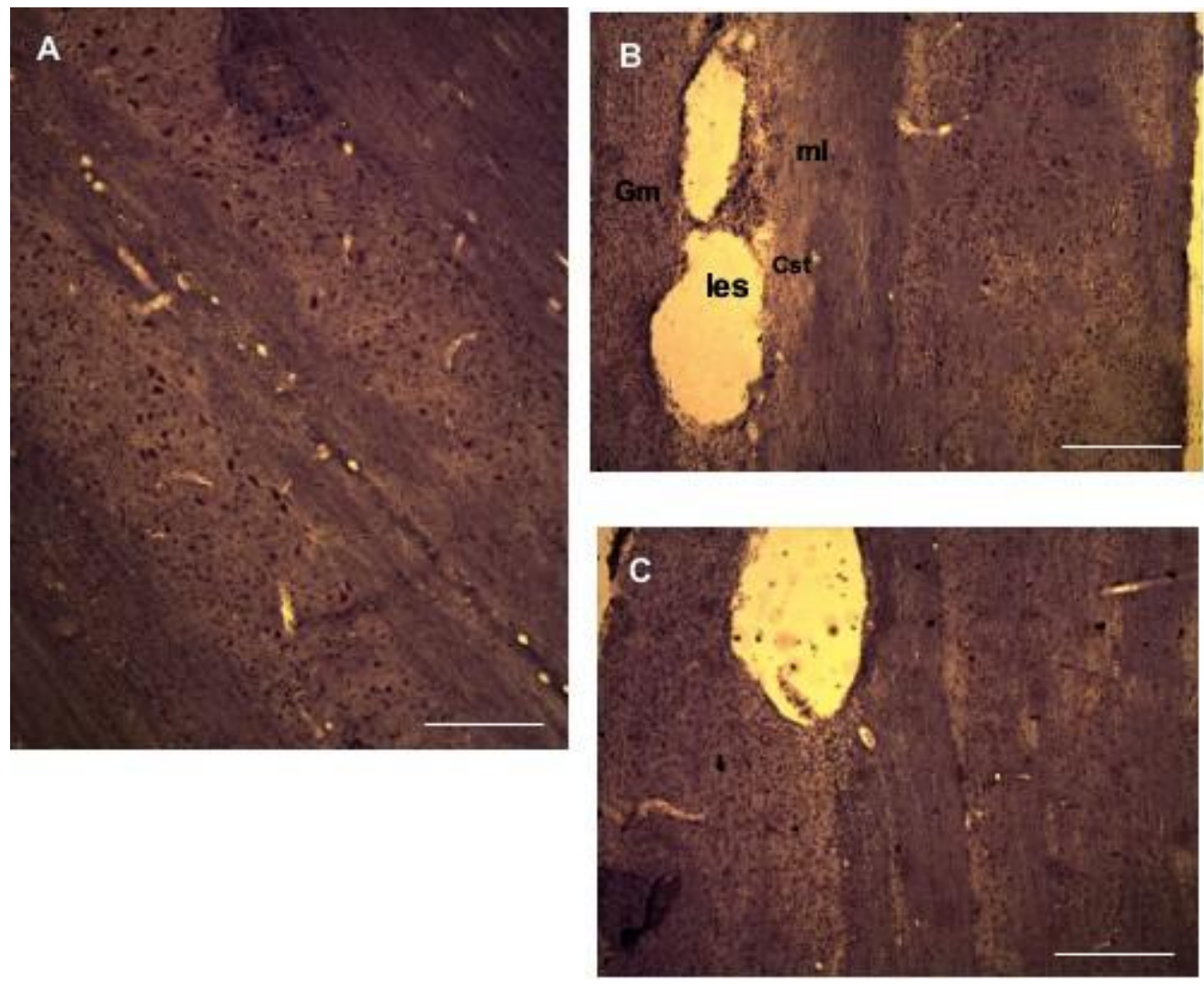

Figure2. A. $20 \mu \mathrm{m}$ thickness of the horizontal section of the whole spinal cord stained with thianine. B. Destruction of the left corticospinal tract and some part of Gray matter $\mathrm{Gm}$. C. The enlarged view of the caudal part of the CST lesion and some part of grey matter; Survival times: 4 weeks, Scale bar: $500 \mu \mathrm{m} ; 200 \mu \mathrm{m}$; $100 \mu \mathrm{m}$. 
The CST can be visualised in thionine- stained coronal and horizontal sections (Fig1 and Fig2). According To Naghmeh K.F., et al., 2003 "At the top cervical level, the CST is $\sim 0.5 \mathrm{~mm}$ in diameter on one side. The electrode originates originated lesions of $\sim 0.5-1.0 \mathrm{~mm}$. The extend of the lesion was detected in a complete serious of adjacent horizontal sections of the whole width of tract in the $1 \mathrm{~mm}$ caudal to the lesion (Fig2,C)". 


\section{The result of histology images of grafted tissue}

\subsection{Histology images of the affect of immune attack on the grafted tissue without the injection of immunosuppressant agent}
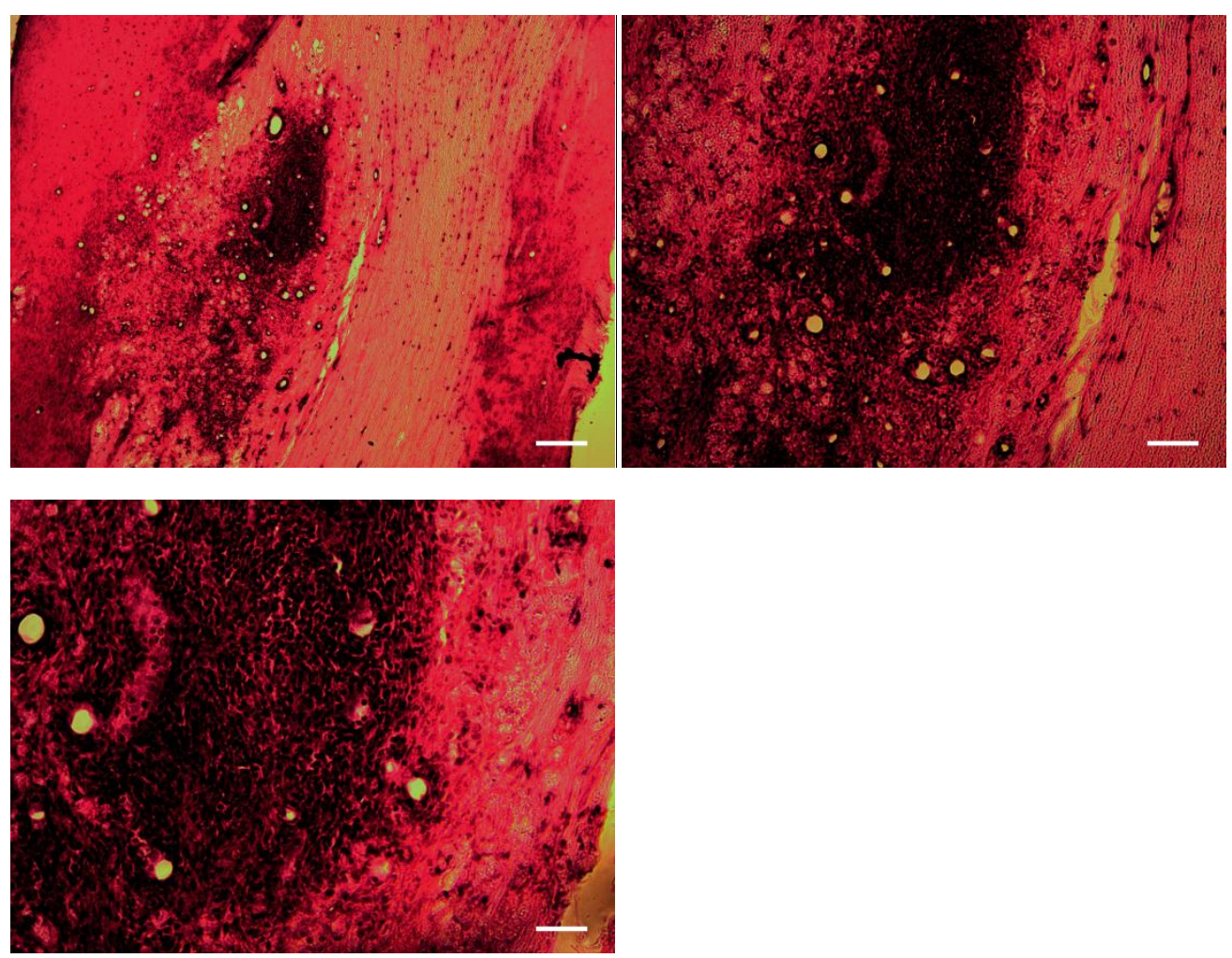

Figure3: Histological assessment of spinal cord tissue immune reaction to xenogenic transplant of OEC without the injection of immunosuppressant agent, the image shows the degenerated cells and the central necrosis and lymphocyte infiltration after 1 week post surgery in lesion area. Survival time: 10 days, Scale bar: $200 \mu \mathrm{m}$. 
Also The histology images show that the animal after 10 days starts immunorjecting the xenotransplanted mice OECs in grafted tissue. Among five groups of animals the one who had survival time of 4 and 1 week did not show any immunorejection and the GFP labeled OEC cells can be visualised and there is not inflammation sign. However the histology images of groups 3, 4 and 5 animals with the survival time of 10-14 days,3,4 and 5 weeks show immune reaction to xenogenic transplant of OEC degenerated cells and the central necrosis and lymphocyte infiltration in lesion area (Fig 3). Moreover, the images of postoperative xenotransplanted OECs under daily subcutaneous injection of $100 \mathrm{ml}$ of a dosage of $6 \mathrm{mg} / \mathrm{kg} /$ day avoid immunorejection e.g (fig4) which shows the misplace of GFP labeled transplanted OECs with the survival time of 4 weeks and there is no sign of inflammation. 


\subsection{Histology images of transplanted olfactory ensheathing cells in displaced position}

after the injection of immunosuppressant agent
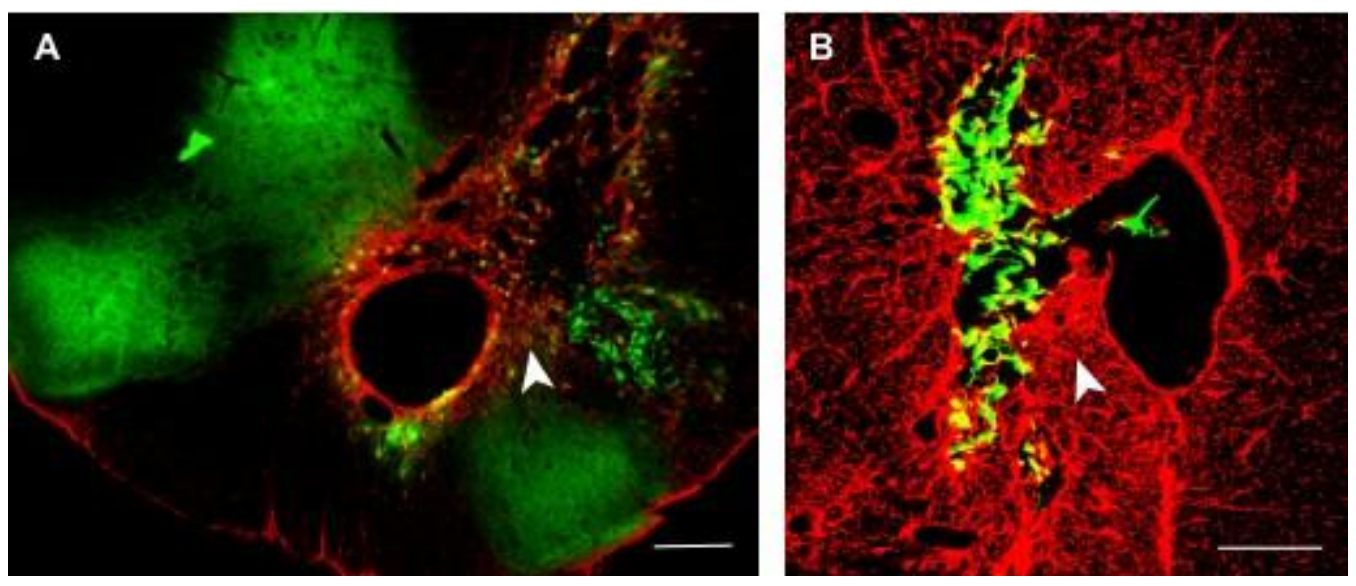

Figure 4: The $20 \mu \mathrm{m}$ thickness coronal section of transplanted CST lesion failure. A. The image shows the GFP labelled grafted OECs at the dorsolateral side of lesion. $B$. The enlarged view of transplanted side show the distance between OEC transplanted and the lesion. Surviving time: 4 weeks; scale bar: A, $100 \mu \mathrm{m} ; \mathrm{B}, 50 \mu \mathrm{m}$. 


\subsection{Histology images of xenotransplanted olfactory ensheathing cells in complete}

corticospinal tract lesion after the injection of immunosuppressant agent
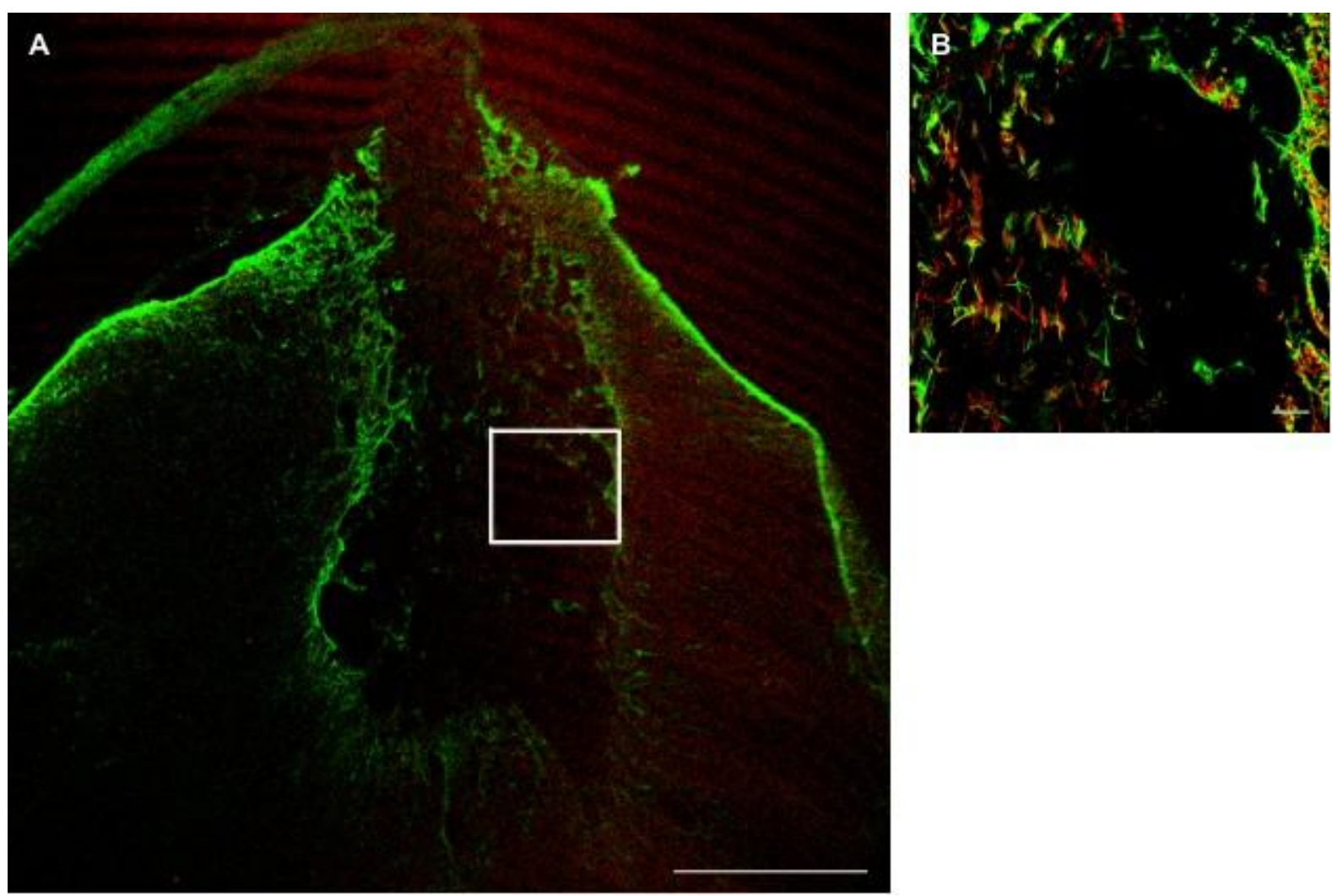

Figure5. A. The regenerated Axon after transplant of olfactory ensheathing cells.B. The image of astrocytes immunostained with an antibody against glial fibrillary acidic protein (GFAP) and axons labeled with red

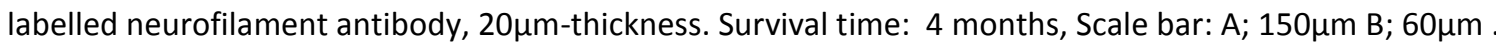



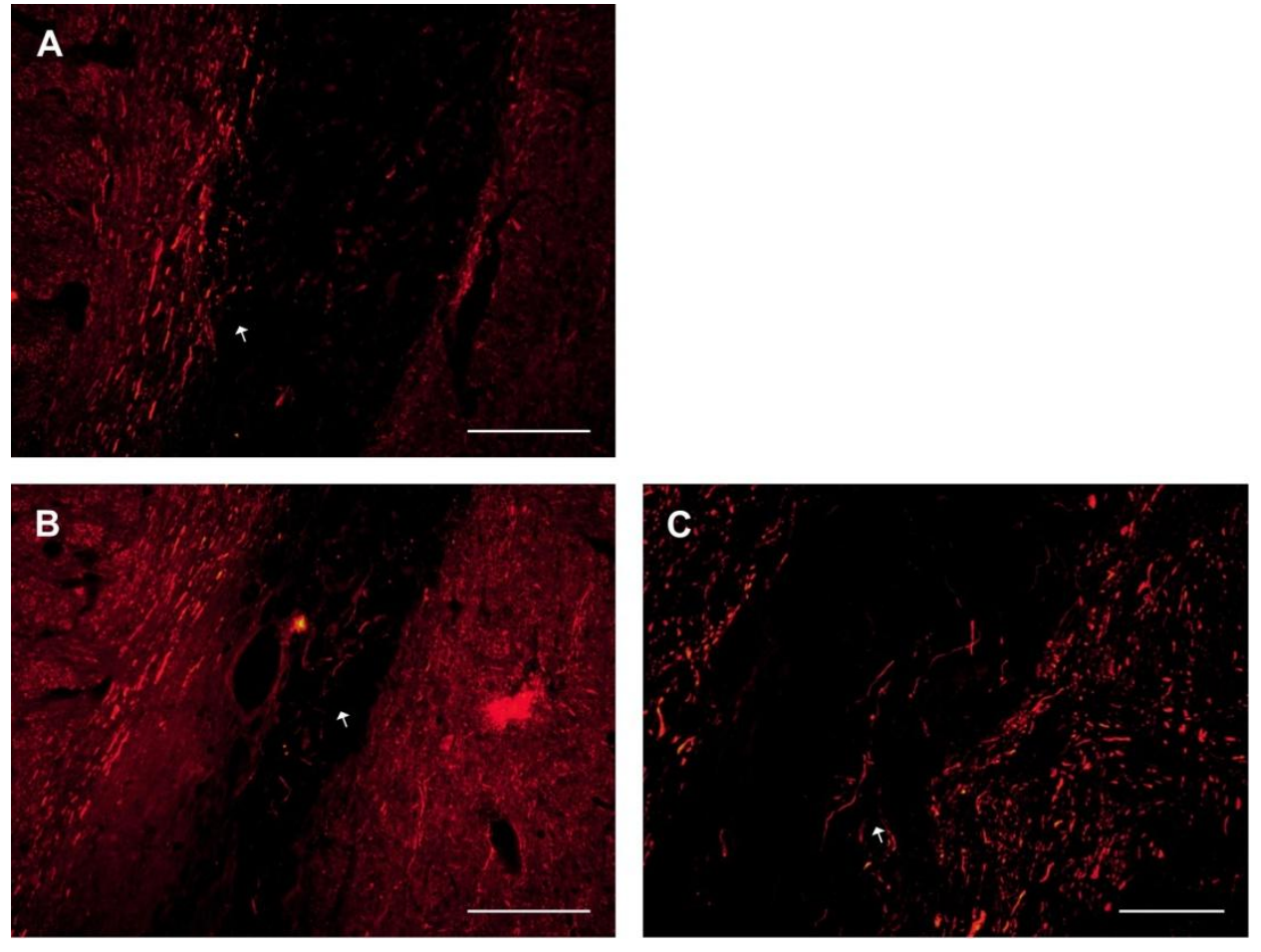

Figure6. A. Reconstructed corticospinal tract after transplantation of OECs, (axons NF, Red). B \& C. Enlargement of regenerated NF labelled axons (red, outlined in A). Horizontal section, Survival time: 4 months, Scale bar: $200 \mu \mathrm{m} ; 200 \mu \mathrm{m} ; 100 \mu \mathrm{m}$. 
The cross and horizontal sections of GFAP and NF staining of 10 animals which have the DFR function return shows the regenerated CST fibres in the lesion area after 8 weeks postoperative. Figure 5 shows the elongated NF stained axons on the right hand side of the lesion however the CST fibers has not been traced to look at the terminal points in Gray matter. The figure 4 shows the cross section of the GFAP labeled astrocytes and NF stained axons in the lesion area which is almost $1 \%$ of total axons. Also The histology images show that the animals after two weeks start immunorjecting the xenotransplanted mice OECs in grafted tissue. Among five groups of animals the one who had survival time of 4 and 1 week did not show any immunorejection and the GFP labeled OEC cells can be visualised and there is not inflammation sign. However the histology images of groups 3, 4 and 5 animals with the survival time of 10-14 days,3,4 and 5 weeks show immune reaction to xenogenic transplant of OEC degenerated cells and the central necrosis and lymphocyte infiltration in lesion area (Fig 3). Moreover, the images of postoperative xenotransplanted OECs under daily subcutaneous injection of $100 \mathrm{ml}$ of a dosage of $6 \mathrm{mg} / \mathrm{kg} /$ day avoid immunorejection e.g (fig4) which shows the misplace of GFP labeled transplanted OECs with the survival time of 4 weeks and there is no sign of inflammation. 


\subsection{Transplant}

The group of 46 As rats which did not show any recovery of DFR function by the end 8 weeks after unilateral lesioning went for further studying on OECS xenotransplant. Of these animals, 7 un-operated AS rats has been left without transplant the period of 8 to 12 months as the long term control. These animals were able to use both paw to reach the pellet and they were tested twice a week for the applied period. The result of behaviour test shows the ability of DFR function of the lesioned paw for the period of 8-12 months as the Graf 4 shows the tissue analysis has been done for further study. The remaining 39 AS rats have been transplanted by OECs. After xenotransplantation all rats were tested for DFR function three times per week for the period of 4 weeks. The result of behaviour test indicated that only 10 rats have recovered and had the ability to reach their lesioned paw through the aperture to grasp the a noodle and their DFR ability continued rising up to 8 weeks after transplantation. However 29 As rats has shown no function return of DFR by the end 4 weeks post operative behaviour test therefore they went through further tissue analysis to find out the reason of failure. The result of histology analysis of grafted tissue proved that the misplaced transplant of GFP-labelled was one of the main reason recovery failure e.g. (fig4) shows the OEC cells has been transplant too deep caudally into anterior gray matter which did not occupy the lesion CST. The other reason of DFR recovery failure in 3 animals were the death of animal few days artery operation or straight away the day after operation which could be due sudden immune reaction to transplanted cells. 


\section{The behaviour test results}

A

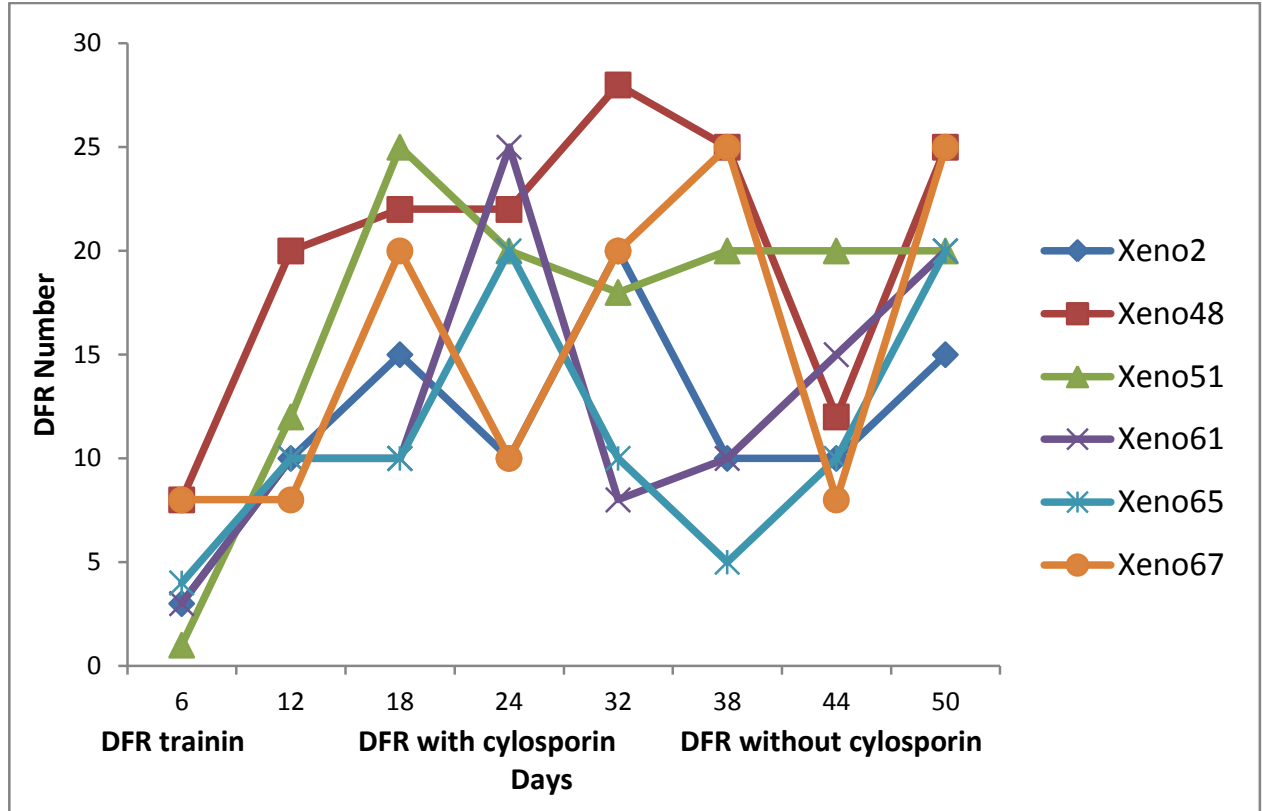

B

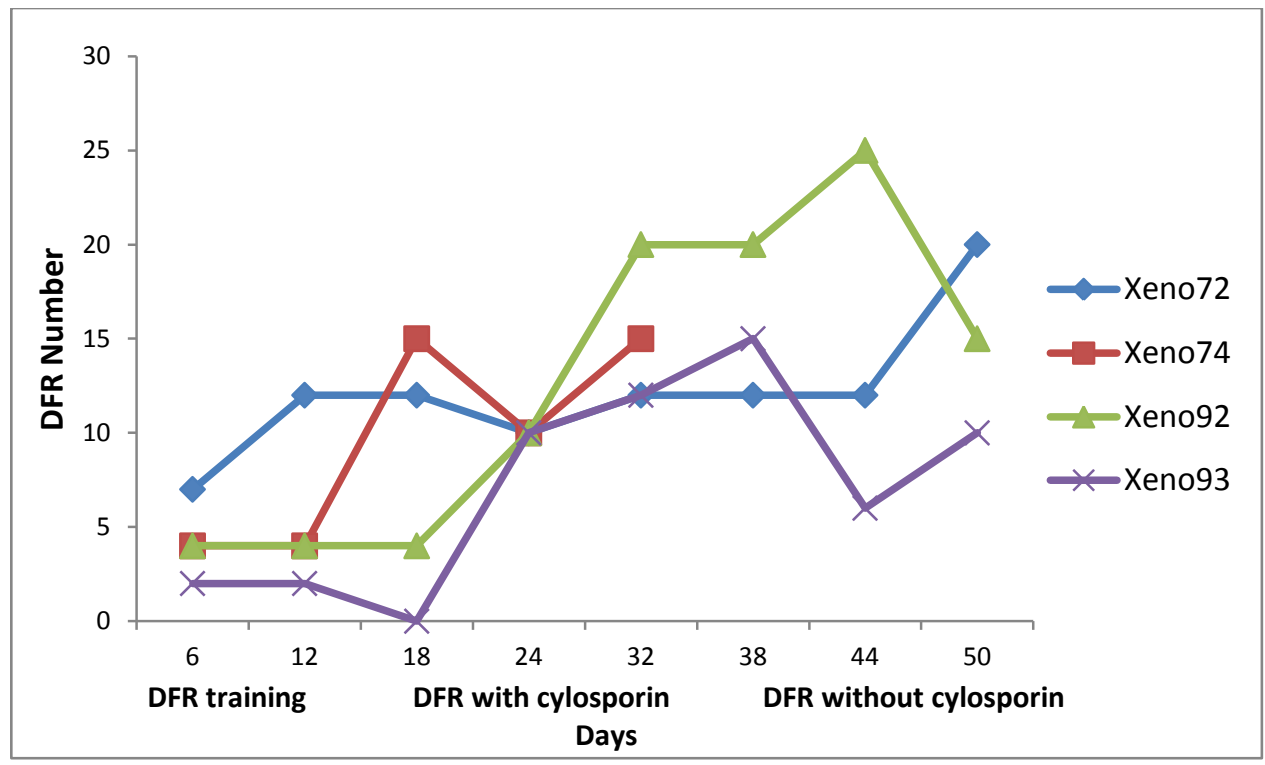

Figure 7: $A$ and $B$ Changes with time in weeks ( $x$-axis) in the number of retrievals ( $y$-axis) performed by the forepaw ipsilateral to the lesion in each testing period (of a total of 50 retrievals by both forepaw. 


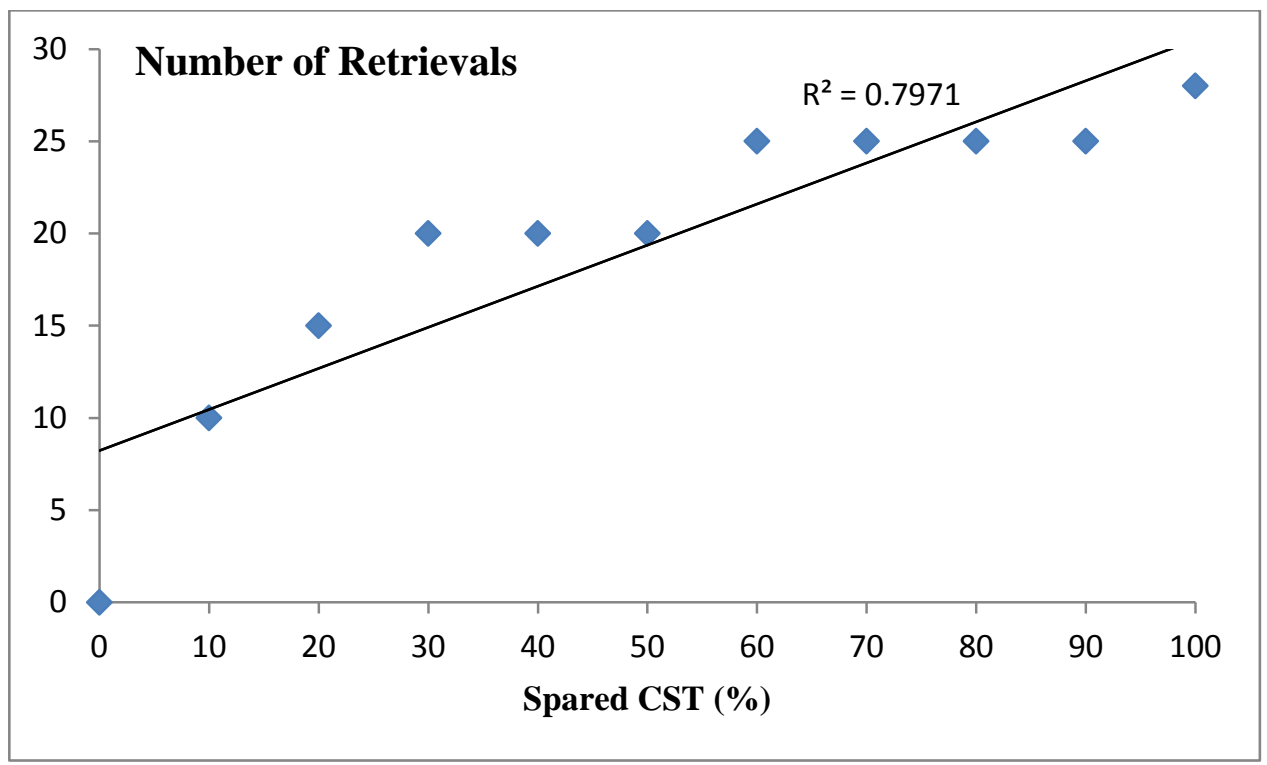

Figure8: A and B Changes with time in weeks ( $x$-axis) in the number of retrievals ( $y$-axis) performed by the forepaw ipsilateral to the lesion in each testing period (of a total of 50 retrievals by both forepaws). The rate of recovery of DFR over the 8 postoperative weeks is proportional to the amount of the CST spared by the lesion. B. Significant correlation $\left(R^{2}=0.79\right)$ between the total number of retrievals by the ipsilateral forepaw $(y$-axis $)$ and the proportion of the CST spared (x-axis). 
There was 10 rats maintain the level of DFR by the ipsilateral forepaw. Following the histology analysis which shows that all samples have some spared CST e.g. (Fig6, A) shows the NF stained spared CST on the left side caudal to lesion. The numerical show the rising curve of DFR over the 8 weeks start reaching from first week in most animals and second and third weeks in 3 rats reaching to almost $50-85 \%$ of the total counting of 30 by the end of 8 weeks. As Fouladi N. et al., 2003 explained "the rate of recovery DFR is proportional to the percentage of spared CST our result shows, the total number of DFR by the ipsilateral forepaw is well correlated with $\left(R^{2}=0.79\right)$ spared axons". 


\subsection{The Immunohistochemistry images of long term untransplated lesion control and behaviour test results}
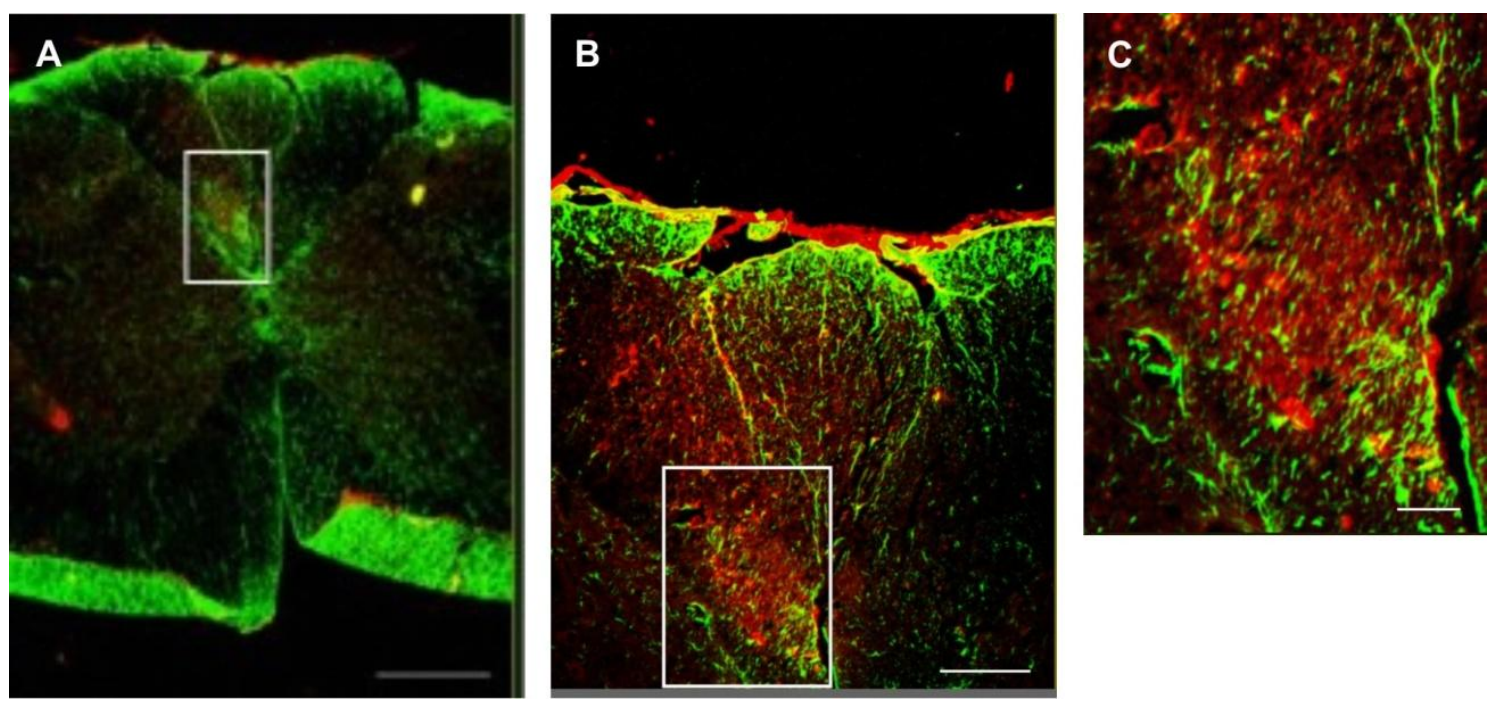

Fig7. A. 20- $\mu \mathrm{m}$-thick coronal section of long term lesion GFAP (Green) and anti-fibronectin (Red) positive (arrows). (B and C) the enlarged view of lesion area, intense GFAP immunoreactivity around the lesion leading to a dense, and "closed" scar completely walling off the central lesion area with astrocytic process passing through the fibrotic scar. C. hypertrophic fibronectin response in lesion central, Survival time: 8 months. Scale bar; $500 \mu \mathrm{m} ; 200 \mu \mathrm{m} ; 50 \mu \mathrm{m}$. 


\section{Chapter 4}

\section{Discussion}

1. The effect of CST Lesions on DFR function

2. Restoration of Function by delayed transplantation

3. The study of grafted tissue immunorejection 


\section{Discussion}

There is an increasing interest in the possibility of using transplantation of xenograft olfactory ensheathing cells to repair trauma to central and peripheral nervous system in the future clinical study. In the current study, we have tried to present the preclinical xenograft delayed transplantation model in AS rat and preventing immune reaction by immunosuppressant agent. The main result is that the reparative effect of delayed xenotransplant of olfactory ensheathing cells in rat animal model is DFR function return which is similar to allograft transplant of OECs in rat animal model as it has been reported by earlier by this group.

\section{The effect of CST Lesion on DFR function}

As it was explained in chapter 2 the total number of 93 animals after being trained for DFR task were under unilateral CST lesion operation using 0.25 diameter built-in thermocouple (TC) temperature sensor electrode. In total 20 rats lost the ability to retrieve their paw unilaterally. As the behaviour test results show these animals lost the ability to reach their paw through the cage slot to grasp the noodle when the number of reaching were counted 30 times three times a week over the 8 weeks postoperative. Therefore animals show 0 times retrieval. This result correlates with histology analysis of lesioned tissue. As you can see at(Figure $2, B \& C$ ) the lesion we produced at the CST tract unilaterally destroyed dorsal CST fibers and slight damage to ascending ( sensory ) dorsal columns totally damaged ipsilateral DFR function and no function return for the maximum period of 12 months. According to the study of Mckenn. et al., 2000 on proteoglycan effect on repair of laminin- 
mediated axon growth, the loss of DFR is associated with impairment of rostral motor neuron innervating proximal muscle which leads to failure in the ability of proximal muscular to extend the forelimb through the slit and it would not cause any failure in grooming, handling food, grasping and walking of the affected forelimb. According to the observation we made at the present study, the lesion we produced at the CST tract unilaterally destroyed dorsal CST fibers and slight damage to ascending ( sensory) dorsal columns totally damaged ipsilateral DFR function and no function return for the maximum period of 12 months.

\section{Restoration of function by delayed transplantation}

In future clinical trial of spinal cord injury xenograft transplant of OECs will be more efficient than allogenic transplant of human OECs from patient olfactory bulb is not feasible and the autotransplant or allotransplant of olfactory mucosa cells is not accessible due to difficulty of finding donors and the problem with the cell number of cultured tissue. At the present study we design rat delayed xenograft transplant model to investigate regeneration of CST fibres and DFR function return after transplanting cells from mice bulb and the effect of stopping immunosuppressant agent (cyclosporine) in DFR function . Recovery of function accrued if the transplanted OECs injected unilaterally in the CST lesion area and the immune attack being suppressed by injecting immusuppressant reagent regularly. As it has been explained in chapter 3 after OEC xenotransplant of total 39 AS rats, 29 rats did not show any DFR function recovery of the lesioned paw due to either misplace of cell transplant in CST dorsal column e.g (fig. 4) the cells being injected 1-2 mm away from the dorsolateral side of the lesion or the immunorejection of CST cells which can be due to the error in the injection of immunosuppressant. Of those xenotransplanted rats 
only 10 rats have recovered from DFR deficit and being able to reach their lesioned paw through the aperture to grasp the a noodle and their DFR ability continued rising up to 8 weeks after transplantation. As the immunogistochemistry analysis proved the xenotransplanted OEC cells migrate caudally in to distal CST and by 10 days postsurgery they form $\sim 100-150 \mu \mathrm{m}$ elongated bridge alongside the nerve axis and allows the CST fibres to cross the lesion area and terminated in dorsal horn e.g (fig6 $A, B \& C$ ). As the results show although we stop daily cyclosporine injection by the end of 3 weeks, the DFR function remains constant as it was prior stopping cyclosporine however; no GFP labelled OEC was visualised under florescent microscope due to immunorejection e.g.(fig5 A\&B). This immunohistochemistry results correlate with numerical data of behaviour test as you can see in ( fig7,A\&B) the number of DFR retrieval after transplanting OEC starts increasing and reached to maximum number of 20 -30 during the first 3 weeks post operative under cyclosporine injection and remains spontaneous up to 4 weeks after stopping cyclosporine injection and although the histology image proved that by stopping cyclosporine xenotransplanted OECs being rejected at week 8 of posts surgery, the immunorejection of grafted tissue did not effect on DFR Recovery and numerical data shows that the animals did not shows deficit only in their paw reaching task and the number of DFR remains spontaneous between 10-30. This result is also consistent with the study of David, Choi. et. al., (2003) who studied on facial nerve xenograft model. The histology analysis shows that $\sim 1 \%$ of the total 50,000 myelinated CST fibres on OEC cells transplanted animals (fig .6 B) shows that regenerated fibres are $\sim 1 \%$ of the total 50,000 myelinated CST fibres on OEC cells transplanted animal and this result is correlated with the number of spared CST fibres with $\mathrm{R}^{2}=0.79$ ( fig 8). These results are also consistent with previous studies by Li et al., 1997 and Naghmeh N., et al., 2003 in allogenic transplant of OEC in unilateral lesioned CST model, our observation in crossspecies transplantation immunorejection indicates that transplanted rats start 
immurejecting OEC cells by 10 days postoperatively. The histological evaluation by haematoxylin- eosin of graft biopsy specimens show tissue necrosis and inflammatory cell infiltration in lesion area which according to the Banff classification of inflammatory reaction was accepted as grade III. However, clinical evaluation of transplanted animal did not show any signs of rejection such as Erythema, odema and hair loss (Cendales LC. et al., 2008).

\section{The study of immunorejection}

Also The histology analysis e.g ( Fig 3) show that the animals after two weeks start Immunorejecting the xenotransplanted mice OECs in grafted tissue. Among five groups of animals group 1 and 2 with the one who had survival time of 4-7 days did not show any immunorejection and the GFP labeled OEC cells can be visualised and there is not any inflammation sign. However the histology images of groups 3, 4 and 5 animals with the survival time of $10-14$ days 3,4 and 5 weeks show immune reaction to xenogenic transplant of OEC degenerated cells and the central necrosis and lymphocyte infiltration in lesion area. Moreover, the images of postoperative xenotransplanted OECs under daily subcutaneous injection of $100 \mathrm{ml}$ of a dosage of $6 \mathrm{mg} / \mathrm{kg} /$ day avoid immunorejection e.g (fig4) which shows the misplace of GFP labeled transplanted OECs with the survival time of 4 weeks and there is no sign of inflammation.

In general in preclinical model different approaches has being used to avoid immunorejection, such as genetically engineered pig expressing the human complemented inhibitor, hCD59 in rat transacted spinal cord which shows axonal regeneration (Imaizumi T. et al., 2000). Our study shows the daily injection of $100 \mathrm{ml}$ of diluted cyclosporine However, the study done by (Feil, et al., 2012) shows the greater survival of groin flaps and reduces in 
calcineur in inhibitor drug toxicity by combination therapy of triptolide and cyclosporine $A$ than recipients treated with cyclosporine A only. Therefore, in our conclusion, the mice xenograft model of 10 AS rats delayed OEC transplant shows the regeneration of damaged cortiocospinal tract and ipsilateral DFR function return, and also the result shows that the daily injection of $100 \mathrm{ml}$ diluted cyclosporine avoids immune attack and reduces inflammatory cells infiltrate in delayed CST ipsilateral rat model and also our study proved that stop of cyclosporine injection would not prevent DFR function and the regenerated fibers can still be visualised.

\section{Future plan:}

The clinical repair of spinal cord damage by olfactory ensheathing cells (OECs) will be one of the main approaches to repair chronic spinal cord injury therapy. As previous studies investigated allogeneic transplant of OEC in animal models and clinical models and also xenograft transplant of OEC have shown the functional repair of damaged fibers and functional return ( David, C. et. al., 2003) (Li et al., 1998 ) ( Fouladi, N., 2003) and (Imaizumi, T. et al., 2000). Although all the studies has proven the efficiency of OEC in improve of functional behaviour and repair of damage axons by bridging along the tissue and myelination of regenerated fibres, it is still difficult to choose the right source and method of cell production. As our study proven primary culture of OECs is not the ideal transplant material in $\mathrm{SCl}$ because they normally survive for few weeks, they get contaminated simply, they are limited in number and it is difficult to generate pure cell population, as Tracy A et al., (2003)found out in the study of improved axonal regeneration by OEC cell line.

The other problem is the use of immunosuppressive drug such as cyclosporine in case of 
nonsynergic cells transplant which may cause various side affect such as nephrotoxicity, hypertension, neurotoxicity, hirsutism, gum hypertrophy (Groen PC,1989) (Miach PJ.,1986). Therefore, it would be better if we can replace different method with immunosuppressive drug to avoid immune attack.

My future plan is to produce transgenic Homogenous OEC clonal cell line (nOEC) and to investigate whether $\mathrm{nOEC}$ have the same characteristic and property in repair of $\mathrm{SCl}$ as primary OEC cell culture or not and whether we can avoid immunorejection by transplanting cells derived from transgenic mice expressing human complemented inhibitory protein, hCD59( membrane cofactor protein) which mediate the removal of microorganism and the clearance of modified self cells which appear to have immunosuppressive effect in transgenic expressing human complement inhibitory protein (Imaizumi T. et al., 2000). Then hopefully, they will be able to apply it in future clinical therapy. 


\section{References:}

Akaoka H, Szymocha R, Beurton-Marduel P, Bernard A, BelinMF, Giraudon P (2001)

Functional changes in astrocytes by human T-lymphotropic virus type-1 T-lymphocytes.

Virus Res78:57-66

ALLT, G. (1975). The node of Ranvier in experimental allergic neuritis: an electron microscope study. J. Neurocytol. 4: 63-76.

Americam spinal injury association Net, http://www.asia-spinalinjury.org/elearning/elearning.php ( accessed 26/06/14)

Anthony N., Van Del Pol and Justin G. Santarelli (2003) Olfactory Ensheathing Cells: Time Lapse Imaging of Cellular Interactions, Axonal Support, Rapid Morphologic Shifts, and Mitosis. The journal of comparative neurology 458: 175-194.

Appel F, Holm J, Conscience JF, Schachner M, (1993), Several extracellular domains of the neural cell adhesion molecule L1 are involved in neurite outgrowth and cell body adhesion. Journal of Neuroscience 13:4764-75.

Barber PC, Raisman G (1978) Replacement of receptor neurones after section of the vomeronasal nerves in the adult mouse. Brain Res 147:297-313.

Barres BA (2008) The mystery and magic of glia: a perspective on their roles in health and disease. Neuron 60:430-440

Barraud P and Seferiadis AA et al. (2010) Neural crest origin of olfactory ensheathing glia. Proc Natl Acad Sci USA 49:21040-5.

B.M. Harrison, (1980) Remyelination by cells introduced into a stable demyelinating lesion in the central nervous system, J. Neurol. Sci. 46,63-81.

Beattle MS, Bresnahan JC, Komon J. et al. (1997) Endogenous repair after spinal cord contusion injuries in the rat. Exp. Neurol. 148, 453-463

Bushong EA, Martone ME, Ellisman MH (2004) Maturation of astrocyte morphology and the establishment of astrocyte domainsduring postnatal hippocampal development. Int J Dev Neurosci. 22:73-86 
Bush TG NP, Horner CH, Polito A, Ostenfeld T, Svendsen CN, Mucke L, Johnson MH, Sofroniew MV (1999) Leukocyte infiltration, neuronal degeneration and neurite outgrowth after ablation of scar-forming, reactive astrocytes in adult transgenic mice. Neuron.23:297308

Brown JT, Cahn-Palay V and Palay SL (1977) A study of afferent input to the inferior olivary complex in the rat by retrograde axonal transport of horseradish peroxidase. J. Comp Neural $175,1-22$.

Brown LT (1971) Projections and terminations of the corticospinal tract in rodents, EXP Erain Res 13, 432-450.

Brockes JP, Fields KL, Raff MC (1979) Studies on cultured rat Schwann cells. I. Establishment of purified populations from cultures of peripheral nerve 1: 105-18

Caroni, P, Savio T and Schwab ME (1988) Central nervous system regeneration: oligodendrocytes and myelin as nonpermissive substrates for neurite growth. Prog. Brain Res.78, 363-370 (1988).

Cendales LC, Kanitakis J, Schneeberger S, et al. (2008) The Banff 2007 working classification of skin-containing composite tissue allograft pathology. Am J Transplant 8:1396-400.

Chuah MI, Au C (1991) Olfactory Schwann cells are derived from precursor cells in the olfactory epithelium. J Neurosci Res 29:172-80

Chauvet N, Prieto M, Alonso G (1998) Tanycytes present in the adult rat mediobasal hypothalamus support the regeneration of monoaminergic axons. Experimental neurology, 1: $1-13$

Chen, P. Goldberg, D. Kolb, B. Lanser and Benowitz L (2002) Axonal rewiring and improved function induced by inosine after stroke. Proc Natl Acad Sci USA 99: 9031-9036

Choya Yoon, Mark H. Tuszynski (2012) Frontiers of spinal cord repair: Experimental Approaches for Repair 1:1-15

Chuah MI, Au C (1993) Cultures of ensheathing cells from neonatal rat olfactory bulbs. Brain Res 601:213-20

Chuah MI, Au C. (1991) Olfactory Schwann cells are derived from precursor cells in the olfactory epithelium. J Neurosci Res 29:172-80. 
Ching-Yi Lin , hing-Yi Lin, Yu-Shang Lee, Vernon W. Lin, and Jerry Silve ( 2012) "Fibronectin inhibits chronic pain development after spinal cord injury", Journal of Neurotrauma, 3:589599

Choi, D, Raisman G(2003) Immune rejection of a facial nerve xenograft does not prevent regeneration and thereturn of function: an experimental study.Neuroscience 2: 501-7.

De Groen PC, (1989) Cyclosporine: a review and its specific use in liver transplantation 6: 680-9

D. Kocsis, (2000) Xenotransplantation of transgenic pig olfactory ensheathing cellspromotes axonal regeneration in rat spinal cord 9: 949-953

Doucette R (1991) PNS-CNS transitional zone of the first cranial nerve. J Comp Neurol 312: 451-66

Bottai D, Cigognini D, Madaschi L, Adami R, Nicora E, Menarini M, et al. (2010) Embryonic stem cells promote motor recovery and affect inflammatory cell infiltration spinal cord injured mice. Exp Neurol 223:452-63

E. Karaoz S, Kabatas G, Duruksu et al., (2012) Reduction of lesion in injured rat spinal cord and partial functional recovery of motility after bone marrow derived mesenchymal stem cell transplantation.Turkish Neurosurgery 2:207-217

Fairless R and Barnett SC (2005) Olfactory ensheathing cells: their role in central nervous system repair. International Journal of Biochemistry and Cell Biology 37: 693-9.

Faulkner, J. R., Herrmann, J. E., Woo, M. J., Tansey, K. E. and Doan, N. B. (2004) Reactive astrocytes protect tissue and preserve function after spinal cord injury. J. Neurosci 9:214355.

Feron F, Perry C, McGrath JJ, et al. ( 1998) New techniques for biopsy and culture of human olfactory epithelial neurons. Arch Otolaryngol Head Neck Surg 124:861-6.

Feinstein, A. (2007) The clinical neuropsychiatry of multiple sclerosis. Cambridge University Press. 8:915-20.

Fitch MT, Silver J (1997) Glial cell extracellular matrix: boundaries for axon growth in development and regeneration. Cell Tissue Res 290:379-384

Fitch MT, Silver J (2008) CNS injury, glial scars, and inflammation inhibitory extracellular matrices and regeneration failure. Exp Neurol 209:294-301. 
Franklin RJ, Gilson JM, Franceschini IA, et al. (1997) Schwann cell-like myelination following transplantation of an olfactory bulb-ensheathing cell line into areas of demyelination in the adult CNS. Glia 17:217-24.

Jike. Lu, K. Ashwell (2002) Olfactory ensheathing cells: their potential use for repairing the injured spinal cord. Spine 27: 887-892.

George T Paxinos (1994) The Rat Nervous System, Hardcover, Academic Press.

Gilmore S.A (1971) Autoradiography studies of intramedullary Schwann cells in irradiated spinal cords of immature rats. Anat. Rec 171:517-528.

Graziadei PP, Monti Graziadei GA (1980) Neurogenesis and neuron regeneration in the olfactory system of mammals. III. Deafferentation and reinnervation of the olfactory bulb following section of the fila olfactoria in rat. J Neurocytol. 9:145-62.

H. W. Park, M. J. Lim, H. Jung, S. P. Lee, K. S. Paik, and M. S.Chang (2010) Human mesenchymal stem cell-derived Schwann cell like cells exhibit neurotrophic effects, via distinct growth factor production in a model of spinal cord injury. Glia 9: 1118-1132.

Hayato Naka, Shiho Nakamura , Takuya Shimazaki ,Hideyuki Okano, Okano Lab (Keio) (2008) Generation of neurospheres from embryonic stem cells for investigating the temporal specification of neural stem/progenitor cells. Protocol Exchange 9:1014-1023.

Hayat S, Wigley CB , Robbins J (2003) Intracellular calcium handling in rat olfactory. Molecular and Cellular Neurosciences 2:259- 27.

Haydon PG (2001) Glia listening and talking to the synapse. Nat Rev Neurosci 2:185-193.

Harsha R Jani, Raisman G (2004) Ensheathing cell cultures from the olfactory bulb and mucosa .Glia, 2:130-7

Halassa MM, Fellin T and Haydon PG (2007) The tripartite synapse: roles for gliotransmission in health and disease. Trends Mol Med 13:54-63.

Houle JD (1991) Demonstration of the potential for chronically injured neurons to regenerate axons into intraspinal peripheral nerve grafts. Experimental Neurology 1:1-9.

J. Gordon Boyd, Ronald Doucette, Michael D. Kawaja (2005). Defining the role of olfactory ensheathing cells in facilitating axon remyelination following damage to the spinal cord. The Faseb Journal 7:694-703.

Jennifer R. Higginson, Susan C. Barnett (2011) .The culture of olfactory ensheathing cells (OECs) - a distinct glial cell type.Exp Neurol 229: 2-9. 
Jerry Silver, Jared H. Miller (2004) Regeneration beyond the glial scar. Nature Reviews Neuroscience 5:146-15.

Jike Lu. (2002) Olfactory Ensheathing Cells: Their Potential Use for Repairing the Injured SpinalCord. Spine 8:887-92.

John A. Kiernan (2005) BARR'S The Human Nervous System, Williams Wilkins, 32-33

Julian Savulescu (1999) Should we clone human beings? Cloning as a source of tissue for transplantation. Journal of Medical Ethics 25:87-95.

Jun WU, Tian-Sheng SUN, Ji-Xin REN ,Xian-Zhang WANG (2008) Ex vivo non-viral vectormediated neurotrophin-3 gene transfer to olfactory ensheathing glia: effects on axonal regeneration and functional recovery after implantation in rats with spinal cord injury. Neuroscience Bulletin 2: 57-65.

John I. Bianco, Chris Perry, Damien G. Harkin, Alan Mackay-Sim (2004) Neurotrophin 3 promotes purification and proliferation of olfactory ensheathing cells from human nose Glia, 2: 111-123

Joosten EA, Schuitman RL, Vermelis ME, Dederen PJ (1992) Postnatal in rat spinal cord: a light and electron microscopic anterograde HRP study. J.Comp. Neural 326, 133-146

Joostan E. A., Schuitman R. L., Vermelis M, E., and Dederen, P.J. (1992) Postnatal development of ipsilateral corticospinal component in rat spinal cord: Alight and electron microspic antrograde HRP study. J.Comp. Neural 326, 133-146.

Joostan, E. A. and Gribnau A. A. (1988). Unmylinated corticospinal axon in adult rat myramidal tract: An electron microscopy microscopic tracer study. Brain Res 459:173-177.

Jike Lu,François Féron, Alan Mackay-Sim, Phil M. E. Waite (2002). Olfactory ensheathing cells promote locomotor recovery after delayed transplantation into transected spinal cord. 125:14-21.

John P.Fraher (1999) Review the transitional zone and CNS regeneration. J.Anat. 194:161 \pm 182 .

Kiernan J A (2005) Barr's the human nervous system: An Anatomical Viewpoint 339-347.

Kieman,J.A.(1979) Hypotesis concerned with axonal regeneration the mammalian nervous system. Biol.Rev.54, 155-197. 
Kenta Watanabe, Kenji Kondo, Tatsuya Yamasoba, Kimitaka Kaga (2007) Age-related change in the axonal diameter of the olfactory nerve in mouselamina propria. Acta Oto Laryngologica. 127:108-112.

Jun Li, Guilherme Lepski (2013 Cell) Transplantation for Spinal Cord Injury: A Systematic Review. BioMed Research International. 4:994-1005.

Liang, F. Y., Moret, V., Wiesendanger, M., and Rouiler, E. M. (1991). Cortico motoneuronal connections in the rat: Evidence from double- labelling of motorneurons and corticospinal axon arborisations. J. Comp Neurol. 311:356-366.

Lu QR, Sun T, Zhu Z, Ma N, Garcia M, Stiles CD, Rowitch DH(2002) Common developmental requirement for Olig function indicates a motor neuron/oligodendrocyte connection. Cell 109:75-86.

Lu P, Tuszynski, M.H (2008) Growth factors and combinatorial therapies for CNS regeneration. Experimental Neurology.209:313-320.

Marie T. Filbin (2003) Myelin -association inhibitors of axonal regeneration in the adult mammalian CNS. Neuro. Neuroscience 4:703-713.

Mattson MP (2008) Glutamate and neurotrophic factors in neuronal plasticity and disease. Ann. N. Y. Acad. Sci. 1444:97-112.

Mckeon, R, J, Hoke, A, \& Silver, J. (1996) Injury induced proteoglycan inhibit the potential for laminin-madiated axon growth on astrocytic scars. Exp. Neural. 136:32-43.

Menei P, Montero-Menei C, Whittemore SR, Bunge RP, Bunge MB(1998) Schwann cells genetically modified to secrete human BDNF promote enhanced axonal regrowth across transacted adult rat spinal cord. European Journal of Neuroscience. 10:607-21.

Miach PJ (1986) Cyclosporin A in organ transplantation. Med. J. 145:146-50.

Monti Graziadei GA, Karlan MS, Bernstein JJ, Graziadei PP(1980) Reinnervation of the olfactory bulb after section of the olfactory nerve in monkey (Saimiri sciureus), Brain Research $2: 343-54$.

Mie Yamamoto , Geoffrey Raisman, Daqing Li, Ying Li (2009) Transplanted olfactory mucosal cells restore paw reaching function without regeneration of severed corticospinal tract fibres across the lesion. 1303:26-31

Mikol DD, Stefansson K (1988) A phosphatidylinositollinked peanut agglutinin-binding glycoprotein in central nervous system myelin and on oligodendrocytes. J Cell Biol 106:1273-9. 
Millar, M.W. (1987). The origin of corticospinal projection neuron in rat. Exp. Brain, Res 67:339-351.

Nagarathnamma Chaudhry, Marie T Filbin (2007) Myelin-associated inhibitory signalling and Strategies to overcome inhibition. J of Cerebral Blood Flow and Metabolism 27:10961107.

Neural development system Net, http://embryology.med.unsw.edu.au/embryology/index.php?title=Neural System Develop ment ,(Accessed 21/06/2014)

Olson HE, Rooney GE, Gross L, Nesbitt JJ, Galvin KE, Knight A, Chen B, Yaszemski MJ, Windebank AJ (2009) Neural stem cell- and Schwann cell-loaded biodegradable polymer scaffolds support axonal regeneration in the transacted spinal cord. Tissue Engineering Part A 15:1797-805.

O. Tsuji, K Miura, K. Fujiyoshi, S. Momoshima, M. Nakamura, H. Okano (2011) Cell therapy for spinal cord injury by neural stem/progenitor cells derived from iPS/ES cells. Neurotherapeutics 4:668-676.

Ou dega M, Xu X (2006) Schwann Cell Transplantation for Repair of the Adult Spinal Cord, Jornal of Neurotrauma 23: 453-467.

Paul Lingor' Nicole Teusch et al. (2007) Inhibition of Rho kinase (ROCK) increases neurite outgrowth on chondroitin sulphate proteoglycan in vitro and axonal regeneration in the adult optic nerve in vivo. Journal of neurochemistry103:181-189.

Perfusion protocol Net, http://www.neuroscienceassociates.com/perf-protocol.htm (Accessed 29/092014)

Pixley S.K. (1992) The olfactory nerve contains two populations of glia, identified both in vitro and in vivo. Glia 5:269-284.

Plenum,NewYork,Bozoyan L, Khlghatyan J, Saghatelyan A (2012) Astrocytes control the development of the migration-promoting vasculature scaffold inthe postnatal brain via VEGF signaling. J Neurosci 32:1687-1704.

Q.Richard Lu, Tao Sun, Zhimin Zhu, et al. (2002) Common Developmental Requirement for Olig Function Indicates a Motor Neuron/Oligodendrocyte Connection. Cell 109:75-86. 
Raisman G (2002) Olfactory ensheathing cells - another miracle cure for spinal cord injury. Nat. Rev. Neurosci 2:369-375.

Raisman G (2004) Myelin inhibitors: does No mean Go. Neuroscience 5:157-161.

R.H. Baloh, M.G. Tansey, P.A. 1998) a novel member of the GDNF ligand family, supports peripheral and central neurons and signals through the GFRalpha3-RET receptor complex. Neuron 21:1291-1302.

Ramon-Cueto A., Avila J. (1998) Olfactory ensheathing glia: Properties and function. [Review]. Brain Research Bulletin 3:175-187.

Ramon-Cueto A, Nieto-Sampedro M. (1992) Glial cells from adult rat olfactory bulb: immunocytochemical properties of pure cultures of ensheathing cells.

Neuroscience 47:213-20.

Ramon-Cueto A, Nieto-Sampedro M.(1994) Regeneration into the spinal cord of transected dorsal root axons is promoted by ensheathing glia transplants.Exp Neurol 127:232-44.

Ramon-Cueto A, Avila J.(1998) Olfactory ensheathing glia: properties and function. Brain Res Bull 46:175-87.

Ramon-Cueto A, Plant GW, Avila J, et al.(1998) Long-distance axonal regeneration in the transected adult rat spinal cord is promoted by olfactory ensheathing glia transplants. J Neurosci 18:3803-15.

Reichardt LF (2006). Neurotrophin-regulated signalling pathways. Philos. Trans. R. Soc. Lond., B, Biol. Sci. 361: 1545-64.

Richard Fairless (2005) Olfactory ensheathing cells: their role in central nervous system repair, The International Journal of Biochemistry \& Cell Biology. 37:693-699.

Schofield AV, Bernard O (2013) Rho-associated coiled-coil kinase (ROCK) signaling and disease. Crit Rev Biochem Mol Biol 48:301-16.

Sofroniew MV (2009) Molecular dissection of reactive astrogliosis and glial scar formation. Trends Neurosci 32:638-647

Seo, Jung Hwa, and Sung-Rae Cho. (2012) Neurorestoration Induced by Mesenchymal Stem Cells: Potential Therapeutic Mechanisms for Clinical Trials", Yonsei Medical Journal 6:10591067. 
Sofroniew MV, Vinters HV (2010) Astrocytes: biology and pathology.Acta Neuropathol 119:7-35.

Sofroniew MV (2009) Molecular dissection of reactive astrogliosis and glial scar formation. Trends Neurosci 32:638-647.

Sinead MG (2009) Sonic hedgehog promotes the generation of myelin proteins by transplanted oligosphere-derived cells", Journal of Neuroscience Research 14: 3067-3075

Tom, V. J., Doller, C. M. \& Silver J. (2002) Promoting regeneration of dystrophic axons. Soc. Neurosci. Abstr. 14:635.

Tracey A. De Lucia; James J. Conners et al., (2003) Use of a Cell Line to Investigate Olfactory Ensheathing Cell-Enhanced Axonal Regeneration. The Anatomical Record 271:61-70

T. Imaizumi, K.L. Lankford, S.G. Waxman, C.A. Greer, J.D. Kocsis, (1998)Transplanted olfactory ensheathing cells remyelinate and enhance axonal conduction in the demyelinated dorsal columns of the rat spinal cord. J. Neurosci 18:6176-6185.

T. Imaizumi, K.L. Lankford, J.D. Kocsis (2000) Transplantation of olfactory ensheathing cells or Schwann cells restores rapid and secure conduction across the transected spinal cord. Brain Res. 854:70-78.

TAAB Laboratory and Microscopy Net, http://www.taab.co.uk/ ( Accessed on 29/09/2014)

Trinh Victoria T., Daniel K. Fahim, Komal Shah et al. (2013) Subcortical Injury Is an Independent Predictor of Worsening Neurological Deficits Following Awake Craniotomy Procedures. Neurosurgery 2:160-9.

Xi-Guang Li, Jon H. Kaas et al., (1990) A real Distributions of Cortical Neurons Projecting to Different Levels of the Caudal Brain Stem and Spinal Cord in Rats. Motor Res 7:315-335.

Yamamoto M, Raisman G, Li D, Li Y (2009) Transplanted olfactory mucosal cells restore paw reaching function without regeneration of severed corticospinal tract fibres across the lesion. Brain Research 15:26-31.

Yaojian Rao,Wenxiao Zhu et al. (2013) Clinical application of olfactory ensheathing cells in the treatment of spinal cord injury. The journal of international medical research 41:473481.

Ying LI, Daqing LI and Geoffry Raisman (2005) Interaction of olfactory ensheathing cells with astrocytes may be the key to repair of tract injuries in the spinal cord. The pathway hypothesis Journal of Neurocytology 34:343-351. 
Ying Li, Pauline M. Field, Geoffrey Raisman (1998) Regeneration of Adult Rat

Corticospinal Axons Induced by Transplanted Olfactory Ensheathing Cells. 24: 1051410524.

Y. Li. Field PM, Raisman G. (1997) Repair of Adult Rat Corticospinal Tract by Transplants of Olfactory Ensheathing Cells Science 277:2000-2.

Y. Iwashita, J.W. Fawcett, A.J. Crang etal., (2000) Schwann cells transplanted into normal and $X$-irradiated adult white matter do not migrate extensively and showpoor long-term survival. Exp. Neurol. 164:292-302.

Ying Li, Field PM, Raisman G. (1998) Regeneration of adult rat corticospinal axons induced by transplanted olfactory ensheathing cells. J Neurosci 18: 10514-24.

Ying Li, Raisman, G. (1995) Sprouts from cut corticospinal axons persist in the presence of astrocytic scarring in long-term lesions of the adult rat spinal cord. Exp. Neurol. 134:102111 .

Vroemen, M. Weidner N (2003) Purification of Schwann cells by selection of p75 low affinity nerve growth factor receptor expressing cells from adult peripheral nerve. Journal of Neuroscience Methods 124:135-143

Wang, $X$ et al., (2000) Localization of Nogo-A and Nogo-66 receptor protein at site of axonmyelin and synaptic contact. J. Neurosci 22:3553-3567.

Whishaw, I.Q., Pellis S.M. (1990) The structure of skilled forelimb reaching in the rat. Bev. Br. Res. 41:49-59

W. L. Huang K. J. George (2007) The characteristics of neuronal injury in a static compression model of spinal cord injury in adult rats. European Journal of Neuroscience 2: 362-372.

Wang, Ying, and Zhi-hui Huang (2012) Morphological phenotypes of olfactory ensheathing cells display different migratory responses upon Slit-2. Experimental Cell Research 15:1889900

Wu, Yan, Li, Chun (2011) Delayed olfactory ensheathing cell transplants reduce nociception after dorsal root injury. Experimental Neurology 49: 312.

Zihlmann, K.B. (2005) The GDNF family members neurturin, artemin and persephin promote themorphological differentiation of cultured ventral mesencephalic dopaminergic neurons. Brain Research Bulletin 68:1-2. 
